\title{
In vivo induction of membrane damage by $\beta$-amyloid peptide oligomers
}

\author{
Carl Julien ${ }^{1,4}$, Colson Tomberlin ${ }^{1}$, Christine M. Roberts ${ }^{1}$, Aumbreen Akram², Gretchen H. Stein ${ }^{3}$, \\ Michael A. Silverman ${ }^{2,5}$ and Christopher D. Link ${ }^{*^{*}}$ (D)
}

\begin{abstract}
Exposure to the $\beta$-amyloid peptide (A $\beta$ ) is toxic to neurons and other cell types, but the mechanism(s) involved are still unresolved. Synthetic A $\beta$ oligomers can induce ion-permeable pores in synthetic membranes, but whether this ability to damage membranes plays a role in the ability of $A \beta$ oligomers to induce tau hyperphosphorylation, or other disease-relevant pathological changes, is unclear. To examine the cellular responses to $A \beta$ exposure independent of possible receptor interactions, we have developed an in vivo C. elegans model that allows us to visualize these cellular responses in living animals. We find that feeding C. elegans E. coli expressing human A $\beta$ induces a membrane repair response similar to that induced by exposure to the CRY5B, a known pore-forming toxin produced by $B$. thuringensis. This repair response does not occur when C. elegans is exposed to an A Gly37Leu variant, which we have previously shown to be incapable of inducing tau phosphorylation in hippocampal neurons. The repair response is also blocked by loss of calpain function, and is altered by loss-of-function mutations in the C. elegans orthologs of BIN1 and PICALM, well-established risk genes for late onset Alzheimer's disease. To investigate the role of membrane repair on tau phosphorylation directly, we exposed hippocampal neurons to streptolysin O (SLO), a pore-forming toxin that induces a well-characterized membrane repair response. We find that SLO induces tau hyperphosphorylation, which is blocked by calpain inhibition. Finally, we use a novel biarsenical dye-tagging approach to show that the Gly37Leu substitution interferes with $A \beta$ multimerization and thus the formation of potentially pore-forming oligomers. We propose that $A \beta$ induced tau hyperphosphorylation may be a downstream consequence of induction of a membrane repair process.
\end{abstract}

Keywords: Alzheimer's disease, $\beta$-amyloid, Tau, Caenorhabditis elegans, Pore-forming toxin

\section{Introduction}

Alzheimer's disease is characterized by the deposition in the brain of senile plaques, composed largely of the $\beta$-amyloid peptide $(\mathrm{A} \beta)$. The amyloid cascade hypothesis posits that in Alzheimer's disease, accumulation of $A \beta$ in the brain ultimately leads to changes in tau metabolism, which leads to the deposition of tau in neurofibrillary tangles (NFTs) that are the likely proximal cause of the neuronal loss observed in this disease [25]. While there is still significant controversy as to whether the amyloid cascade hypothesis explains Alzheimer's pathology $[28,39,72]$, there is extensive evidence (in vitro and in vivo) that exposure of neurons to $A \beta$ can lead to tau hyperphosphorylation, a potential driver

\footnotetext{
* Correspondence: linkc@colorado.edu

${ }^{1}$ Department of Integrative Physiology, University of Colorado at Boulder, Boulder, CO, USA

Full list of author information is available at the end of the article
}

of tau deposition [23, 51, 87]. Multiple tau kinases have been identified (reviewed in [57]), as have pathways by which these kinases could be activated to increase tau phosphorylation $[15,55,89]$. CDK5 and GSK3 $\beta$ have emerged as strong candidates for disease-relevant tau kinases [27, 50], and activation of both these kinases can occur downstream of calpain activation. Calpains are calcium-dependent proteases that can cleave P35 to produce P25, a strong activator of CDK5 [81] or directly truncate GSK3 $\beta$, leading to its activation [34]. Many studies have also demonstrated that exposure of neurons to $A \beta$ can lead to calcium influx $[30,77,78]$ and thus there exists a well-supported molecular mechanism explaining how $\mathrm{A} \beta$ exposure can lead to tau hyperphosphorylation. Less clear is the biological rationale for $A \beta$-induced tau phosphorylation. Is this a selected function of $A \beta$, an indirect consequence of an evolved interaction of $A \beta$ with cells, or an essentially

(c) The Author(s). 2018 Open Access This article is distributed under the terms of the Creative Commons Attribution 4.0 International License (http://creativecommons.org/licenses/by/4.0/), which permits unrestricted use, distribution, and 
random interaction with potentially deleterious outcomes?

Addressing "why" $\mathrm{A} \beta$ induces tau phosphorylation is complicated by uncertainty as to what, if any, selected function the $A \beta$ peptide has. Similarly unresolved is how extracellular $A \beta$ induces intracellular increases in calcium. $\mathrm{A} \beta$ toxicity in numerous models can be attenuated by blocking the NMDA-type glutamate receptor [5, 11, 24], suggesting that this calcium channel could be responsible for A $\beta$-dependent calcium influx. Similarly, the prion protein has been claimed to be a receptor for $A \beta$ oligomers $[7,44,74]$ and to moderate $A \beta$-dependent calcium influx [67]. Other studies have implicated AMPA glutamate receptors $[2,73,88]$ or L-type voltage gated calcium channels [4] in cytoplasmic calcium increases resulting from A $\beta$ exposure. While multiple calcium channels could be involved in $A \beta$-dependent calcium influx, other studies suggest that $A \beta$ oligomers could act independently of endogenous calcium channels by directly forming a calcium-permeable pore. It has long been known that synthetic $A \beta$ can form ion-permeable channels in synthetic membranes [6], a finding that has often been replicated $[29,41,71]$. Although ring-like structures of $A \beta$ oligomers have been visualized by atomic force microscopy in synthetic membranes [46], $A \beta$ membrane pores in pathologically-relevant cells have not been directly visualized or assayed.

One approach to determining if $A \beta$ pores are relevant to $A \beta$ neurotoxicity is to identify substitutions in the $A \beta$ sequence that block pore formation in synthetic membranes, and then determine if these substitutions alter A $\beta$ toxicity. Kim et al. [41] noted a sequence motif (Gly-XXX-Gly-XXX-Gly) present in both the C terminus of $\mathrm{A} \beta$ and the transmembrane domains of bacterial channel proteins, and they proposed that this motif (the "glycine zipper") could facilitate $\alpha$-helical interactions driving $A \beta$ oligomer assembly in membranes and subsequent pore formation. These researchers demonstrated that leucine substitutions at these glycine residues (particularly Gly ${ }^{37} \mathrm{Leu}$ ) prevented synthetic A $\beta$ 1-42 from forming ion channels in synthetic membranes and also significantly reduced $A \beta$ toxicity in Neuro $2 \mathrm{~A}$ cells. Fonte et al. [20] extended these results and demonstrated that the $\mathrm{Gly}^{37}$ Leu substitution both reduced $A \beta$ toxicity in an in vivo transgenic $C$. elegans model that expresses human $A \beta$ and prevented synthetic $A \beta$ oligomers from inducing tau hyperphosphorylation in hippocampal neurons. Peters et al. [68] subsequently demonstrated that a pentapeptide derived from the glycine zipper sequence (GLMVG) inhibited $A \beta$ synaptotoxicity. These observations are consistent with pore formation underlying $A \beta$ neurotoxicity, but they do not directly demonstrate pore formation, and they cannot exclude other interpretations, such as the possibility that the glycine zipper substitutions interfere with interactions with specific cell surface receptors.

An alternative approach to inferring pore formation by $\mathrm{A} \beta$ is to look for its ability to induce a known biological response to exogenously induced pores, rather than attempting to image the pores themselves. Andrews and colleagues have defined a membrane repair pathway that occurs in response to exposure to streptolysin O, (SLO), a well-characterized bacterial pore-forming toxin [32]. As outlined in Fig. 1, this multi-step repair pathway involves: 1) calcium influx through the SLO pore, 2) fusion of local lysosomes with the plasma membrane, releasing

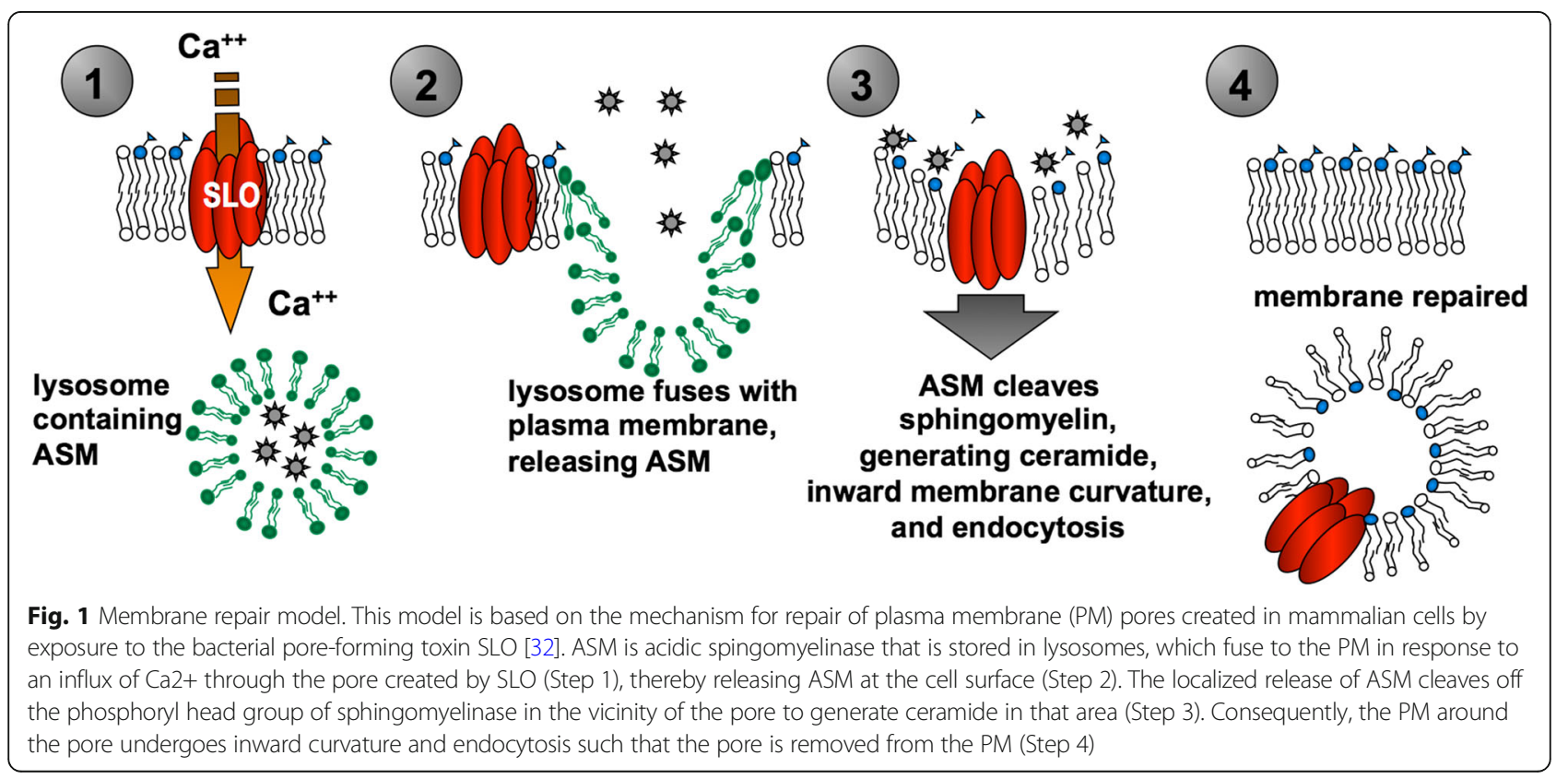


lysosomal contents, 3) cleavage of nearby sphingolipids in the outer leaflet of the plasma membrane by lysosomally-derived acid sphingomyelinase, thereby inducing localized inward membrane curvature, and 4) removal of the pore-containing plasma membrane by endocytosis. While different membrane repair mechanisms are apparently employed for different classes of pore-forming toxins [19], if $A \beta$-induced calcium influx results from an SLO-analogous pore, three strong predictions can be made: 1) A $\beta$ exposure will induce sphingomyelinase-dependent endocytosis, 2) non-toxic $A \beta$ variants (e,g., $A \beta_{42}$ Gly $\left.{ }^{37} \mathrm{Leu}\right)$ will be incapable of inducing membrane repair because they cannot appropriately oligomerize to form membrane pores, and 3) exposure to pore-forming toxins will mimic the effects of $\mathrm{A} \beta$ oligomers, specifically the hyperphosphorylation of tau. Here we test these predictions using a novel $C$. elegans model and primary cultures of rat hippocampal neurons.

Transgenic C. elegans strains have been constructed that express human $A \beta_{42}[16-18,47,82]$, and these strains have a variety of phenotypes, depending on where the transgene is expressed. A confound of these models is that the detectable $A \beta$ is intracellular when assayed by immunohistochemistry, so the degree of outside-in $A \beta$ toxicity (i.e., extracellular $A \beta$ affecting neighboring cells) is unclear. To circumvent this limitation, we have developed a "feeding" model, where C. elegans is fed $E$. coli engineered to secrete human $\mathrm{A} \beta$, and the cellular effects of this exogenous peptide are assayed in intestinal cells. One rationale for this model is that the $C$. elegans intestine does not express candidate $A \beta$ receptors (e.g., prion protein, NMDA glutamate receptors, $\alpha 7 \mathrm{nAChR}$, etc.), and thus any physiological response to $A \beta$ is unlikely to be receptor-mediated. The transparency of $C$. elegans and the existence of relevant transgenic reporter strains allows the effects of $A \beta$ exposure to be followed in live intact animals. Using this model, we show that exposure to wild type $A \beta_{42}$ (but not $A \beta_{42}$ Gly ${ }^{37}$ Leu) induces acid-sphingomyelinase-dependent endocytosis that parallels the response to a known pore-forming toxin, CRY5B. We find that this response to $A \beta$ is calpain-dependent and is altered by loss-of-function mutations in the C. elegans orthologs of BIN1 and PICALM, two Alzheimer risk genes identified in genome-wide association studies [61, 84]. In hippocampal cultures, we show that the SLO pore-forming toxin induces calpain-dependent tau phosphorylation in primary neurons. Furthermore, exogenous sphingomyelinase itself can induce increased tau phosphorylation in these neurons. Finally, we use a novel tagging method to show that the $\mathrm{Gly}^{37}$ Leu substitution does inhibit $\mathrm{A} \beta$ multimerization in a cellular context, thereby rationalizing why this $A \beta$ variant is incapable of inducing membrane repair or tau phosphorylation. Taken together, these results support the view that tau hyperphosphorylation may be a downstream consequence of a membrane repair process, and that exogenous $A \beta$ can induce membrane repair because of its ability to oligomerize into membrane pores.

\section{Materials and methods}

\section{C. elegans strains and maintenance}

C. elegans strains were generally maintained at $20^{\circ} \mathrm{C}$ using standard methods [8]. Strains containing the rynEx60 transgene were passaged at $25^{\circ} \mathrm{C}$ to select for retention of this pha-1 rescuing extrachromosomal transgene.

C. elegans strains used in this study.

\begin{tabular}{ll}
\hline Strain & Genotype \\
\hline KWN117 & $\begin{array}{l}\text { pha-1(e2123) III; him-5(e1490) V; } \text { rnyEX60 (vha-6::mCherry, } \\
\text { Pmyo-3:: GFP, pha-1 rescuing fragment) }\end{array}$ \\
GK280 & $\begin{array}{l}\text { unc-119(ed3) III; dkls166(Popt-2::GFP::pgp-1; unc-119 } \\
\text { rescuing fragment) }\end{array}$ \\
CL6651 & $\begin{array}{l}\text { asm-1(tm5267) II; pha-1(e2123) III; him-5(e1490) V; } \text { rnyEX60 } \\
\text { pha-1(e2123) III(?); amph-1(ok3443); him-5(e1490) V (?); } \\
\text { CL6626 }\end{array}$ \\
rnyEX60 \\
CL6605 & $\begin{array}{l}\text { unc-11(e47) I; pha-1(e2123) III (?); him-5(e1490) V (?); rnyEX60 } \\
\text { CL6623 }\end{array}$ \\
Clp-4(ok2808) III; him-5(e1490) V (?); rnyEX60 \\
RT327 & $\begin{array}{l}\text { unc-119(ed3) III; pwIS72[Pvha-6::GFP::rab-5, unc-119 } \\
\text { rescuing fragment) }\end{array}$ \\
\hline
\end{tabular}

\section{Construction of $E$. coli feeding strains}

To engineer $E$. coli strains capable of secreting human $\mathrm{A} \beta$, plasmids were constructed by inserting the wild type or Gly ${ }^{37}$ Leu $A \beta$ sequence between the NcoI and SacI sites of the arabinose-inducible pBAD gIII vector (Invitrogen), yielding pCL241 and pCL242, respectively. These plasmids were transformed into $E$. coli strain LMG194, allowing tight control of arabinose induction.

\section{Feeding protocol and endosome scoring in C. elegans}

Overnight cultures of $E$. coli strains were diluted 1:100 in Luria broth $(+100 \mu \mathrm{g} / \mathrm{mL}$ ampicillin $)$ and grown for 2 $\mathrm{h}$ in an orbital shaker at $37^{\circ} \mathrm{C}$. Twenty percent arabinose was added to final concentration of $0.2 \%$, and the cultures were grown for another hour. These E. coli cultures were then spread on NGM plates (nematode growth media, [8]) containing $0.2 \%$ arabinose and $100 \mu \mathrm{g} / \mathrm{mL}$ ampicillin and used the next day. L4 worms were transferred onto the fresh plates and allowed to feed for $4 \mathrm{~h}$ at $25^{\circ} \mathrm{C}$. Worms were imaged with a Zeiss Axiophot microscope (40X objective) and endosomes were counted in the anterior $50 \mu \mathrm{m}$ of the intestine.

\section{Hippocampal neuronal culture}

Different protocols were used for the preparation of hippocampal neurons in the Stein and Silverman labs. 
Results obtained in replicate experiments using the two different protocols were highly reproducible.

(Stein lab) Hippocampal neurons were isolated from rat E18 hippocampus (BrainBits, LLC) according to the supplier's protocol. The neurons were plated at 10-20,000 cells $/ \mathrm{cm}^{2}$ on Lab-Tek CC2 4-well chamber slides coated with poly-D-lysine (Sigma P0899) and grown at $37^{\circ} \mathrm{C}$. The medium, Neurobasal $+2 \%$ B27 and $0.5 \mathrm{mM}$ GlutaMax (Invitrogen), was supplemented with $25 \mathrm{mM}$ glutamate for the first 4 days; thereafter the neurons were fed twice a week with medium lacking glutamate and were used for experiments after 9-16 days in vitro (DIV).

(Silverman lab) Primary hippocampal neuronal cultures from E18 embryonic rats (Charles River, USA) of either sex were prepared as described by Kaech and Banker [35] and kept in PNGM primary neuron growth media (Lonza, Basel, Switzerland). The glial feeder layer was derived from murine neural stem cells as described by [59]. All experiments with animals were approved by and followed the guidelines set out by the Simon Fraser University Animal Care Committee, Protocol 943-B05.

\section{SLO activation and treatment of cells}

SLO (Aalto Bio Reagents), a thiol-activated pore-forming toxin that loses activity upon storage at $-70^{\circ} \mathrm{C}$, was reactivated before each experiment by incubating an aliquot of $3 \mathrm{mg} / \mathrm{ml} \mathrm{SLO}$ (in Tris-buffered saline, $\mathrm{pH}$ 8.5) with an equal volume of $20 \mathrm{mM}$ DTT for $10-15 \mathrm{~min}$ at room temperature. Activated SLO and vehicle were diluted with medium and added directly to the cells as $6 \mathrm{X}$ concentrates, or half the old medium on the cells was removed and replaced by a $2 \mathrm{X}$ concentration of SLO or its vehicle control. The toxicity of each aliquot of activated SLO was evaluated by exposing rat insulinoma cells (RIN5F in RPMI 1640 with 10\% Hyclone FBS) to $0-2000 \mathrm{ng} / \mathrm{ml}$ SLO for $2 \mathrm{~h}$ and measuring viability by the reduction of MTT (Sigma M5655). The results indicated that SLO had little or no gross toxicity at $\leq 200$ $\mathrm{ng} / \mathrm{ml}$ and killed half the cells at $600-800 \mathrm{ng} / \mathrm{ml}$. We treated neurons with $50-100 \mathrm{ng} / \mathrm{ml}$ SLO for $1-2 \mathrm{~h}$.

\section{Treatment with calpain inhibitor (PD 150606)}

PD150606 (Sigma D5946) was dissolved in DMSO, aliquoted and stored at $-20^{\circ} \mathrm{C}$. It was added to cells at a final concentration of $30 \mu \mathrm{g}$.

\section{Treatment with sphingomyelinase}

Ten units of lyophilized B. cereus sphingomyelinase (SMase, Sigma S7651) were dissolved in $200 \mu$ l of cold $50 \%$ glycerol in sterile $\mathrm{Ca}^{2+} / \mathrm{Mg}^{2+}$ free PBS, yielding 50 $\mathrm{mU} / \mu \mathrm{l}$. Because SMase loses activity even when stored at $-70^{\circ} \mathrm{C}$, it was best used fresh. Neurons were treated with vehicle control and SMase diluted to $2.5 \mathrm{mU} / \mathrm{ml}$ in Neurobasal/B27 for $2 \mathrm{~h}$.

\section{Antibodies for immunostaining neurons or C. elegans}

Primary antibodies used to stain neurons were mouse monoclonal PHF1 to p-Ser396/p-Ser404 tau (kind gift from Dr. Peter Davies), mouse monoclonal AT8 to p-Ser202/p-Thr205 tau (Pierce, Thermo) and rabbit polyclonal K9JA to total tau (Dako A0024). Secondary antibodies (goat anti-rabbit IgG Alexa Fluor 488, goat anti-mouse Alexa Fluor 594 and donkey anti-mouse IgG Alexa Fluor 555) and Prolong Gold Antifade mounting medium were from Invitrogen. The biarsenical dye used was from the TC-FlAsH ${ }^{\mathrm{m}}$ II In-Cell Tetracysteine Tag Detection Kit (Molecular Probes, Eugene, OR). The anti-RME-1 antibody was obtained from the Developmental Studies Hybridoma Bank, and anti-A $\beta$ mouse monoclonal 6E10 was purchased from BioLegend.

\section{Immunocytochemistry}

Neurons grown on chamber slides (Stein lab) were fixed for $15 \mathrm{~min}$ in $4 \% \mathrm{p}$-formaldehyde/4\% sucrose, permeabilized $7 \mathrm{~min}$ in $0.25 \%$ Triton X-100, and blocked $1-2 \mathrm{~h}$ with $5 \%$ goat or sheep serum (all solutions in PBS). Slides were stained with primary antibodies (K9JA at 1:500, and AT8 or PHF1 at 1:50), secondary antibodies at 1:500, and mounted with ProLong Gold AntiFade. Images were obtained by using a defined scanning pattern to view the total tau fluorescence in sequential fields in each well, capturing images of fields with an average number of cells (typically 5-20 cells per field) using a 10X or 20X objective on a Zeiss Axioskop epifluorescence microscope equipped with 3i Slidebook image analysis software. Identical conditions and exposure times were used to capture an average of 18.5 fields of cells for each treatment presented in our figures, and the ratio of p-tau to t-tau was determined for each image. The mean for each treatment was calculated and compared to its control, and Student's t-test was used to determine if the difference of the means was significant. Similarly, neurons grown on coverslips (Silverman lab) were fixed in $4 \%$ paraformaldehyde for $15 \mathrm{~min}$, blocked in $0.5 \%$ fish skin gelatin and $0.1 \%$ Triton X-100 in PBS, and immunostained with K9JA and AT8 or PHF1. In this case, to quantify tau phosphorylation, histograms were generated using ImageJ from the fluorescence intensity of each pixel across several images, and the average intensity was calculated [20]. Appropriate thresholds were applied to eliminate background signal before histogram analysis, and 17 images per experimental condition were analyzed from at least three independent neuronal cultures.

\section{Preparation of $A \beta$ oligomers}

$A \beta$ oligomers were prepared from synthetic $A \beta$ (BioSynthesis) using the "ADDL" preparation originally described by Lambert et al. [43], and subsequently used by 
us to characterize wild type and Gly ${ }^{37}$ Leu oligomers [20]. Briefly, peptides were solubilized in hexafluoroisopropanol (HFIP) and desiccated in microfuge tubes, then dissolved in fresh, anhydrous DMSO (Sigma Hybri-Max D-2650) to make a $\sim 5 \mathrm{mM}$ solution. This solution was then diluted to $\sim 100 \mu \mathrm{M}$ with cold F12 media without phenol red (Biosource) and aged $24 \mathrm{~h}$ at $4{ }^{\circ} \mathrm{C}$. The samples were centrifuged at $14,000 \mathrm{~g}$ for $10 \mathrm{~min}$ at $4{ }^{\circ} \mathrm{C}$ to remove any insoluble material, and the supernatants stored at $4{ }^{\circ} \mathrm{C}$.

\section{Immunoblotting}

Neurons were treated with vehicle, SMase, SLO, and PD 150606 as described above and lysed in RIPA buffer containing Complete Protease Inhibitor Cocktail (Roche) and Halt Phosphatase Inhibitor Cocktail (Thermo Fisher). Samples $(10 \mu \mathrm{g})$ were resolved on 10\% SDSpolyacrylamide gels and transferred to polyvinylidene fluoride (PVDF) membranes. Membranes were incubated with the following primary antibodies overnight at $4{ }^{\circ} \mathrm{C}$ : PHF-1 (1:1000), AT8 (1:250), K9JA (1:2000), and anti-tubulin (1:1000). The membranes were imaged using Fujifilm LAS4000 Luminescent Imager. Densitometric scanning and quantitative analysis were carried out using ImageJ.

For assaying $A \beta$ expression in engineered $E$. coli strains, bacterial cultures were spun down in a tabletop centrifuge (3 min at 10,000 rpm), and pellets were frozen at $-80^{\circ} \mathrm{C}$ until use. Pellets were solubilized in RIPA buffer supplemented with AEBSF (Sigma P2714) and quantitated using Pierce BCA Protein Assay (Thermo Fisher 23,225). Protein samples were boiled in sample buffer (4\% BME in NuPAGE LDS sample buffer (Invitrogen NP0007) and run at $180 \mathrm{~V}$ on NuPAGE $4-12 \%$ Bis-Tris Gels (Invitrogen, NP0321) using MES SDS Running Buffer (Invitrogen NP0002). Gels were transferred to $0.45 \mu \mathrm{m}$ supported nitrocellulose (GE Osmonics WP4HY00010) using 20\% methanol, $39 \mathrm{mM}$ glycine, $48 \mathrm{mM}$ Tris base at $21 \mathrm{~V}$ for 108 min. Prestained Rainbow size markers (Amersham Biosciences RPN755) were used to size bands. Blots were visualized by Ponceau stain, boiled for $3 \mathrm{~min}$ in PBS, blocked in TBS-Tween $+5 \%$ milk (100 mM Tris7.5, 150 $\mathrm{mM} \mathrm{NaCl}, 0.1 \%$ Tween-20) and probed with $\mathrm{A} \beta$ antibody 6E10 (BioLegend 803,002) at a 1:1000 dilution. Secondary HRP-conjugated antibody (Sigma A5906 mouse) was used, and the blot was developed in ECL Plus (Amersham RPN2132).

Treating hippocampal neurons with Cys-tagged $A \beta$ peptides Rat hippocampal neurons (cultured in the Stein lab) were treated with wild-type and Cys-tagged $A \beta$ peptides (synthesized by Bio Synthesis) and exposed to the FlAsH dye according to manufacturer's instructions with modifications [TC-FlAsH ${ }^{\mathrm{sm}}$ II In-Cell Tetracysteine Tag
Detection Kit (Molecular Probes)]. Briefly, rat hippocampal neurons were treated to $10 \mu \mathrm{M}$ EDTA to suppress background fluorescence for $10 \mathrm{~min}$, and were then exposed to $2.5 \mu \mathrm{M}$ Cys-tagged $\mathrm{A} \beta$ peptides or wild-type $\mathrm{A} \beta$ peptides for $1 \mathrm{~h}$ at $37^{\circ} \mathrm{C}$. FlAsH dye was then applied to neurons at 1:800 for $30 \mathrm{~min}$. BAL wash buffer was used to remove the excess of the FlAsH dye and was replaced by warm HBSS after $15 \mathrm{~min}$. Neurons were then immediately fixed and prepared for immunohistochemistry.

\section{Microscopy}

A Zeiss Axiophot microscope equipped with digital deconvolution optics and a Nikon Structured Illumination Super-resolution (Light Microscopy Core Facility in Department of Molecular, Cellular and Developmental Biology, University of Colorado Boulder) were used for imaging C. elegans and rat hippocampal neurons. Images generated in the Silverman lab were acquired using a Leica DMI6000B inverted epifluorescence microscope using a 63 X 1.4 N.A. oil-immersion objective equipped with a cooled CCD camera controlled by MetaMorph (Molecular Devices).

\section{Statistical analysis}

A one-tailed paired two sample for mean t-test, was used to determine significance between pair wise comparisons of control and experimental conditions. Log rank statistics were used to analyze survival curves in the CRY5B exposure experiments (Fig. 5b). Significant differences between the treatments were analyzed by t-tests with equal or unequal variance at a $95 \%$ confidence interval. The experiments were carried out in three different cultures and at least 60-70 cells were analyzed per condition. For the blots, cell lysates were collected from at least 3 cultures.

\section{Results}

$A \beta$ induces a membrane repair process in $C$. elegans To assay the ability of human $A \beta$ to induce membrane repair in an in vivo model, we took advantage of previous work by Aroian and colleagues, who studied the effects of the CRY5B toxin on C. elegans [31, 38, 85]. The CRY5B protein is a member of the "Bt crystal" collection of pore-forming toxins secreted by Bacillus thuringiensis. To visualize the effects of CRY5B on C. elegans intestinal cells, these researchers used a transgenic reporter strain that expresses a fluorescent fusion protein, specifically localized to the lumen of the intestine, to monitor endocytosis following exposure to an E. coli strain engineered to express CRY5B. We have replicated these experiments (Fig. 2a, right top panel), and as previously reported [52], exposure to CRY5B results in a significant induction of endocytosis, a component of the intestinal membrane repair process. In parallel, we engineered $E$. coli to secrete $\mathrm{A} \beta$ 1-42, using the arabinose-inducible vector $\mathrm{pBAD}$ gIII, 


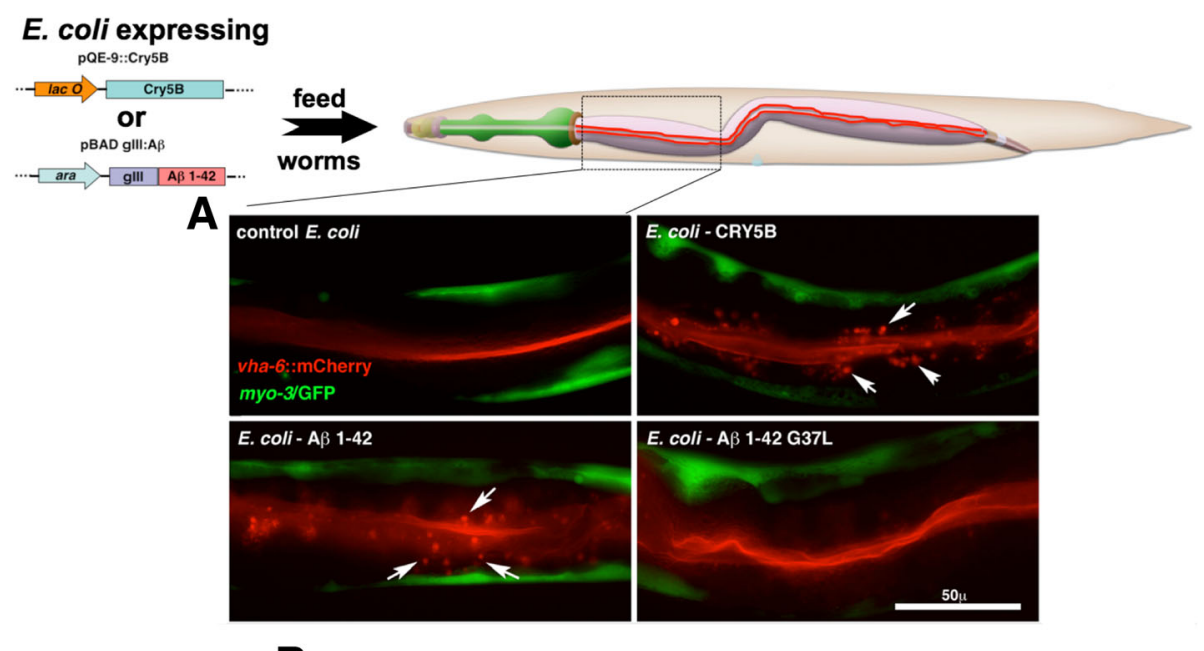

B
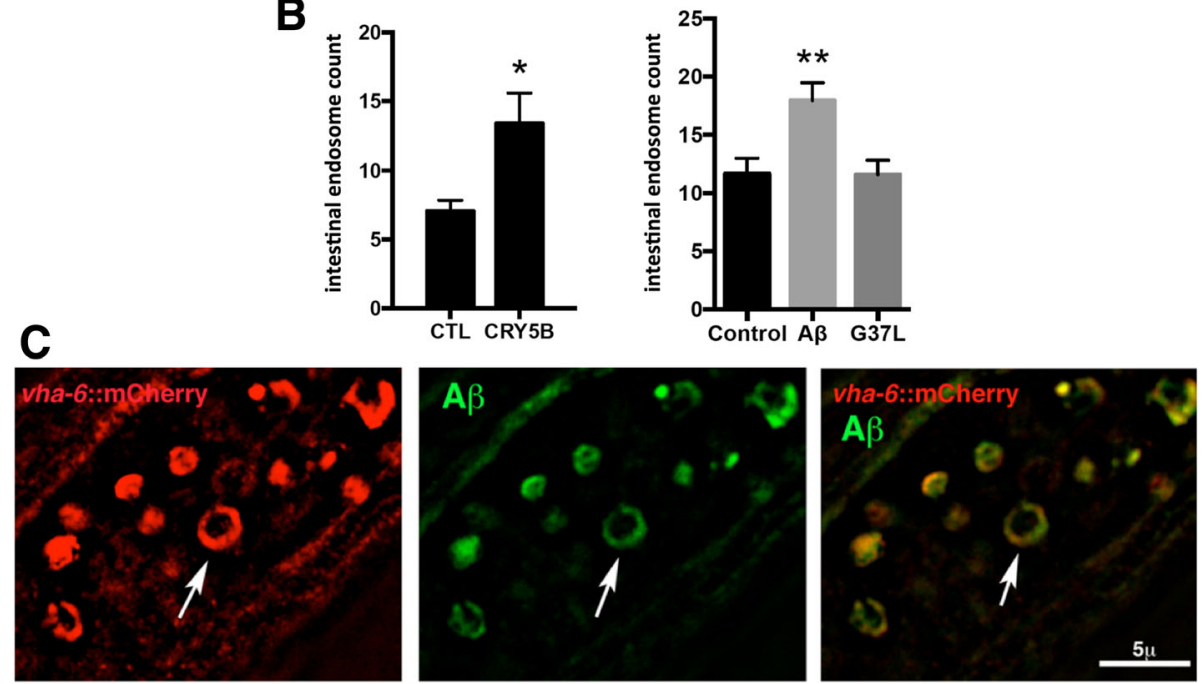

Fig. 2 Induction of intestinal endosomes in C. elegans fed E. coli that express human A $\beta$ peptide. a Live images of C. elegans reporter strain KWN117 (vha-6:mCherry) fed E. coli expressing either vector control, CRY5B toxin, wild type $A \beta_{1-42}$, or $A \beta_{1-42}$ Gly ${ }^{37}$ Leu. Note that both CRY5B and wild type $A \beta_{1-42}$ induce intestinal endosomes (arrows) containing the vha-6:mCherry reporter usually associated with the lumenal membrane of the intestine. This induction does not occur in worms fed $E$. coli expressing the non-pore-forming $A \beta_{1-42}$ Gly ${ }^{37}$ Leu variant. b Quantification of endosome induction. c Super resolution image of intestinal endosomes induced in strain KWN117 by wild type $A \beta_{1-42}$. The treated worm was subsequently fixed, permeabilized, and probed using anti-A $\beta$ antibody 6 E10. Note that the A $\beta$ staining co-localizes with the membrane-associated vha-6:"mCherry reporter (arrow), not the endosomal lumen. ${ }^{*} p<0.05$ and ${ }^{* *} p<0.01$ when compared with the vehicle control

and exposed reporter strain KWN117 (vha-6::mCherry) to those induced E. coli cultures. As shown in Fig. 2a, this resulted in an induction of endocytosis similar to that observed in the CRY5B-exposed worms. The increased intestinal vesicles observed in these experiments could be labeled with endosomal marker RAB-5::GFP or immunostained with antibodies against the endosomal RME-1 protein, demonstrating that these vesicles are indeed endosomes (Additional file 1: Figure S1 A, B). Importantly, this induction of endocytosis was not observed in KWN117 worms exposed to an E. coli strain expressing the Gly ${ }^{37}$ Leu variant of $A \beta$, which we have previously shown to be non-toxic in mammalian neurons [20]. (The engineered E. coli strain expressing the $\mathrm{A} \beta_{42}$ Gly ${ }^{37}$ Leu variant actually produces higher levels of $A \beta$ peptide than the $A \beta_{42}$ wild type strain when assayed by immunoblot, Additional file 1: Figure S1C).

If the intestinal endosomes induced by exposure to $\mathrm{A} \beta$-expressing $E$. coli were in fact a result of a membrane repair process similar to that proposed by Andrews and colleagues (Fig. 1), our expectation was that these endosomes would contain membrane-associated $A \beta$ that had been endocytosed from the luminal plasma membrane. We therefore fixed and permeabilized KWN117 reporter worms fed $E$. coli expressing $A \beta$, then immunostained with an $A \beta$-specific antibody (mAB 6E10). Super-resolution microscopy revealed cytoplasmic rings in intestinal cells that contained both the VHA-6::mCherry luminal marker and 
$A \beta$ (Fig. 2b). We interpret these rings as cross-sections of endosomal vesicles containing both membrane-associated $A \beta$ and VHA-6::mCherry, consistent with the pore-removal-by-endocytosis model proposed by Andrews and colleagues. A critical component of this model is the initial exocytosis of acid sphingomyelinase, a lysosomal enzyme that when released extracellularly can cleave sphingomyelin in the outer leaflet of the plasma membrane lipid bilayer. This conversion of sphingomyelin to ceramide can lead to inward membrane curvature, which is thought to promote local endocytosis (Fig. 1). To test further whether the $C$. elegans response to $A \beta$ exposure paralleled the Andrews model, we repeated the feeding experiments using a derivative of the vha-6::mCherry reporter strain that contained the asm-1 (tm5627) mutation, a deletion allele of a sphingomyelinase gene expressed in the intestine. We observed that loss of asm-1 blocked endosome induction by feeding with CRY5B or A $\beta$-expressing $E$. coli (Fig. 3), again supporting the Andrews model.

To explore the possibility that some genes implicated in Alzheimer's disease might also be involved in the A $\beta$-induced membrane repair process, we examined the effects of loss-of-function mutations in amph-1, unc-11, and $c l p-4$ on A $\beta$-induced endocytosis. Amph-1 is the $C$. elegans ortholog of BIN1, a gene associated with Alzheimer's risk in multiple genome-wide association studies $[10,75]$. BIN1 is a member of the Bin1/amphiphysin/ RVS167 (BAR) family of proteins that are involved in diverse cellular processes, including endocytosis. Unc-11 is orthologous to PICALM, another well-established late onset Alzheimer's disease (LOAD) risk gene known to play a role in clathrin-mediated endocytosis [40]. clp-4 encodes one of nine C. elegans calpains, and we have previously noted that this specific calpain is upregulated both in a transgenic $C$. elegans model of $A \beta$ toxicity [26] and in worms exposed to CRY5B [31]. The CLP-4 calpain also activates the $C$. elegans CDK5 ortholog via cleavage of p35 to p25 [58], and thus has functions analogous to human calpains $1 / 2$, which are required for $A \beta$-induced tau phosphorylation via p25 activation of CDK5 [50, 81]. As shown in Fig. 4a, introduction of either an amph-1 deletion allele or an $u n c-11$ null allele (e47) into the vha-6::mCherry reporter background led to a significant increase in endosomes induced by $\mathrm{A} \beta$ feeding. (Similar results were observed when these genes were knocked down by RNAi, or if CRY5B exposure was used to induce endocytosis, Additional file 1: Figure S2 A, B.) In contrast, introduction of a $c l p-4$ deletion allele blocked the increase of endosomes induced by A $\beta$ feeding. The effects of the $c l p-4$ deletion can also be mimicked by pre-treating the reporter strain with a specific calpain inhibitor, PD150606 (Fig. 4b).

To examine the epistatic relationship between these genes, we repeated the $A \beta$ feeding assay after knocking down amph-1 or unc-11 by RNAi in the reporter strain, with and without the $c l p-4$ mutation. We found that the increased endocytosis induced by amph-1 RNAi was completely blocked by the clp-4 loss-of-function mutation, and the increased endocytosis induced by unc-11 RNAi was somewhat reduced (Fig. 4c). Thus, $c l p-4$ is fully epistatic to amph-1 and may moderate unc-11 in the membrane repair process.

If $c l p-4$ plays a general upstream role in membrane repair, loss of $c l p-4$ should also block induction of endocytosis by CRY5B, and should be deleterious when C. elegans is challenged by this pore-forming toxin. As observed for $\mathrm{A} \beta$ feeding, introduction of the $c l p-4$ deletion allele into the vha-6::mCherry reporter completely blocked endosome induction by CRY5B feeding (Fig. 5a). CRY5B
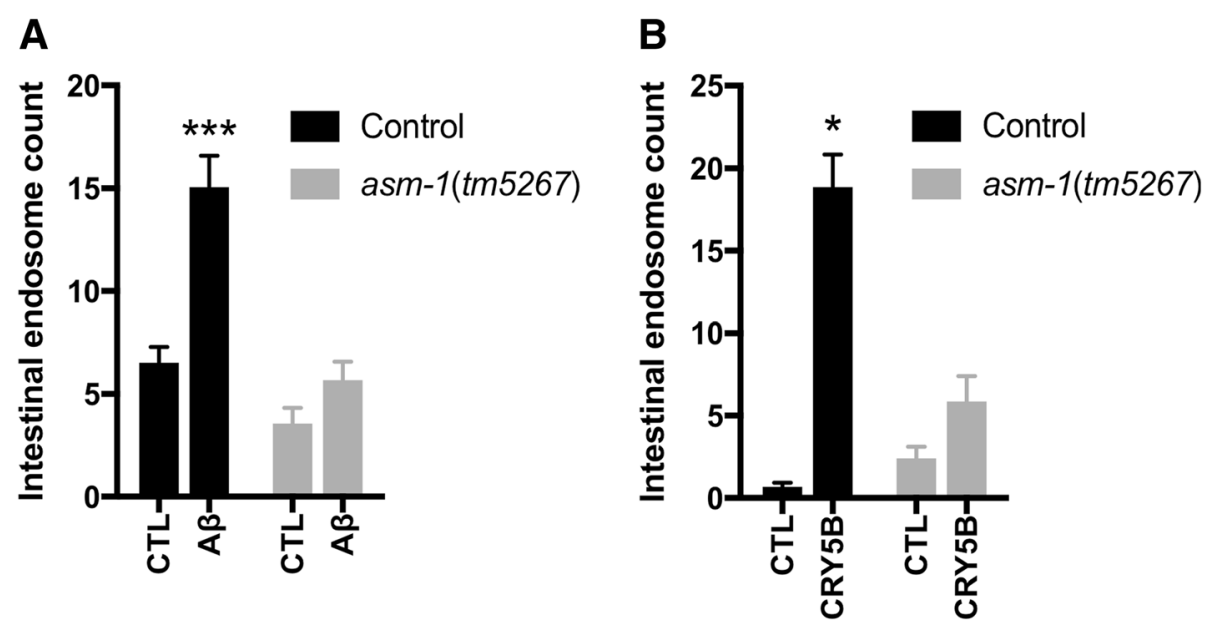

Fig. 3 Induction of intestinal endosomes is blocked by a mutation in the acid sphingomyelinase gene asm-1. a Introduction of the asm-1(tm5267) deletion allele into reporter strain KWN117 blocks the ability of E. coli expressing wild type A $\beta_{1-42}$ to induce intestinal endosomes. $\mathbf{b}$ The asm-1(tm5267) mutation also blocks endosome induction by the CRY5B toxin. ${ }^{*} p<0.05$ and ${ }^{* * *} p<0.001$ when compared with the vehicle control 

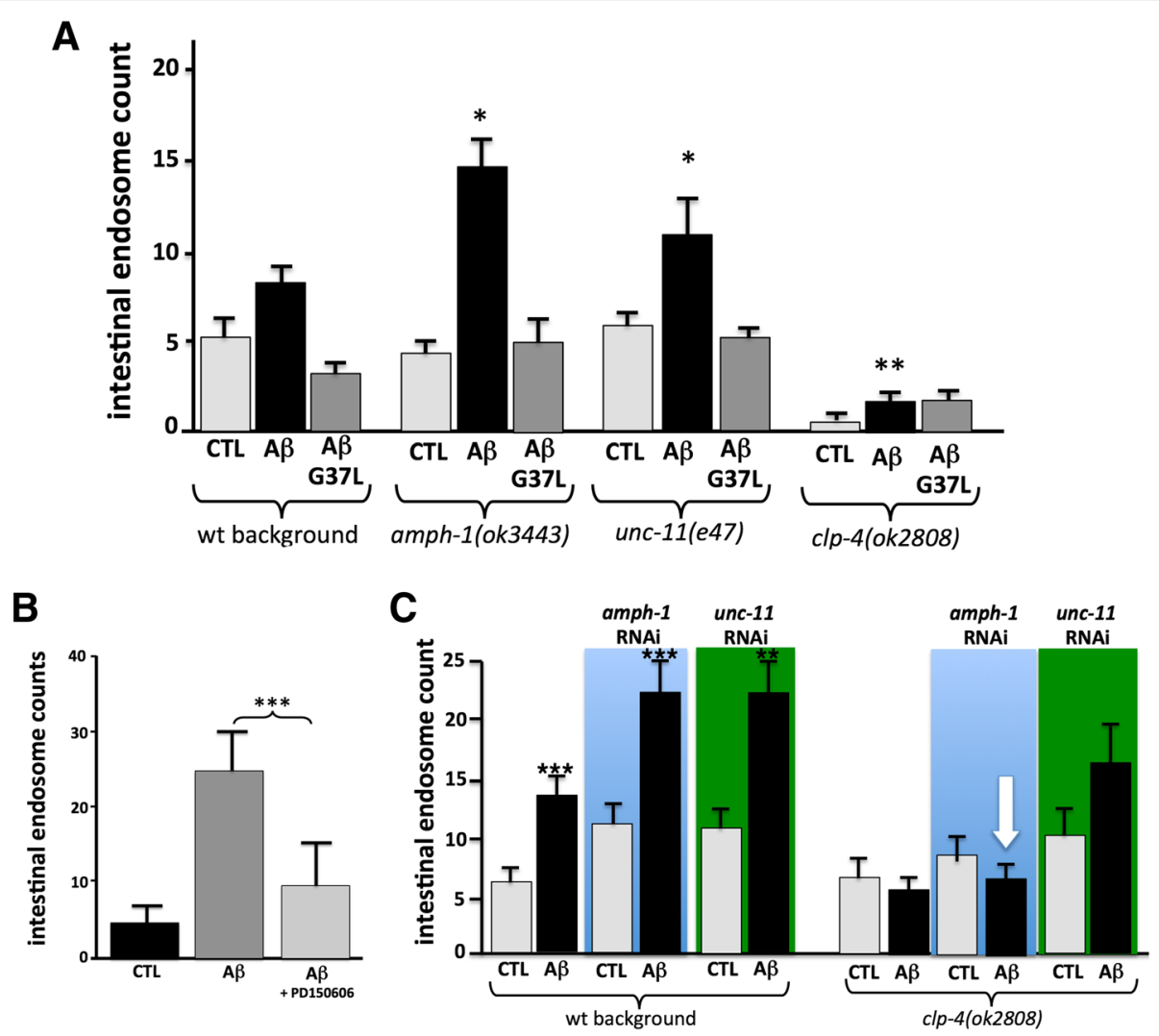

Fig. 4 Effects of amph-1, unc-11 and $c \mid p-4$ mutations on AB-induced intestinal endosomes. a Strains containing the vha-6:mCherry reporter and deletion mutations in amph-1, unc-11, or clp-4 were fed $E$. coli expressing wild type $A \beta_{1-42}$. Note that the amph-1 and unc-11 mutations increase, while the $c / p-4$ mutation decreases, the accumulation of intestinal endosomes. b Treatment with the calpain inhibitor PD150606 replicates the ability of the $c / p-4$ mutation to block $A \beta$-induced increases in intestinal endosomes. c RNAi treatments indicate the clp-4 deletion mutation is epistatic to the effects of amph-1 and unc-11 knockdown. ${ }^{*} p<0.05,{ }^{* *} p<0.01$ and ${ }^{* *} p<0.001$ when compared with the vehicle control
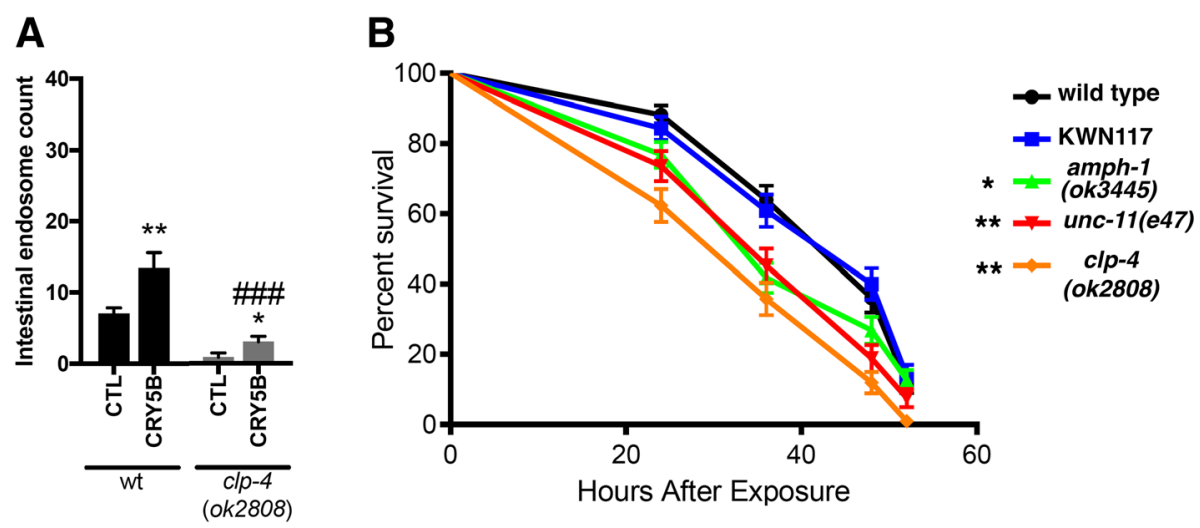

Fig. $5 \mathrm{clp}-4$ deletion blocks endosome induction by CRY5B and sensitizes worms to CRY5B toxicity. a Induction of endosomes induced by CRY5B is blocked by the $c / p-4(0 k 2808)$ deletion mutation. ${ }^{*} p<0.05$ when compared with the vehicle control. \#\#\# $<0.001$ when compared with the wt background. $\mathbf{b}$ Survival curves of C. elegans strains exposed to $E$. coli expressing CRY5B. Note that all three mutations that alter endosome accumulation also sensitize worms to CRY5B toxicity. ${ }^{*} p<0.05,{ }^{* *} p<0.01$ compared to wild type control. NS = not significant 
exposure can be lethal in C. elegans, with most worms dying within 2 days [85]. We found that loss of clp-4 significantly reduced the survival rate in worms exposed to CRY5B (Fig. 5b). Interestingly, both the amph-1 deletion and the $u n c-11$ mutation also significantly decreased survival after CRY5B exposure, suggesting that dysregulation of the membrane repair process may generally sensitize $C$. elegans to this toxin.

\section{Induction of membrane repair increases tau} phosphorylation in hippocampal neurons

The $C$. elegans studies described above demonstrate that $\mathrm{A} \beta$ exposure can lead to a calpain-dependent induction of membrane repair. Multiple groups, including ours, have shown that hippocampal neurons exposed to $A \beta$ oligomers show increased tau phosphorylation [14, 20, 76], and previous studies have also implicated calpain in this process [42, 62]. However, as C. elegans does not express any tau-like molecules in intestinal cells [21], we could not use the worm model to directly investigate the possibility that tau hyperphosphorylation is a downstream consequence of $\mathrm{A} \beta$-induced membrane repair. We thus turned to cultured hippocampal neurons to test this hypothesis, which predicts that insults that induce membrane repair should also induce calpain-dependent tau phosphorylation. To induce membrane damage in hippocampal neurons we exposed them to streptolysin $\mathrm{O}$ (SLO), the bacterial pore-forming toxin used to establish the Andrews membrane-repair model. We observed that hippocampal neurons treated with $50 \mathrm{ng} / \mathrm{ml}$ SLO had increased tau phosphorylation at both the AT8 (Ser 202/Thr 205) and PHF1 (Ser 396/Ser 404) epitopes, assayed either by immunofluorescence (Fig. 6a) or immunoblot (Fig. 6b) (See Additional file 2, Individual Experiment Data). Critically, SLO induction of tau hyperphosphorylation was blocked by treatment with the calpain inhibitor PD150606 (Fig. 6b), demonstrating that tau hyperphosphorylation in response to a pore-forming toxin was calpain-dependent.

As an independent test of the hypothesis that activation of membrane repair can lead to tau hyperphosphorylation,

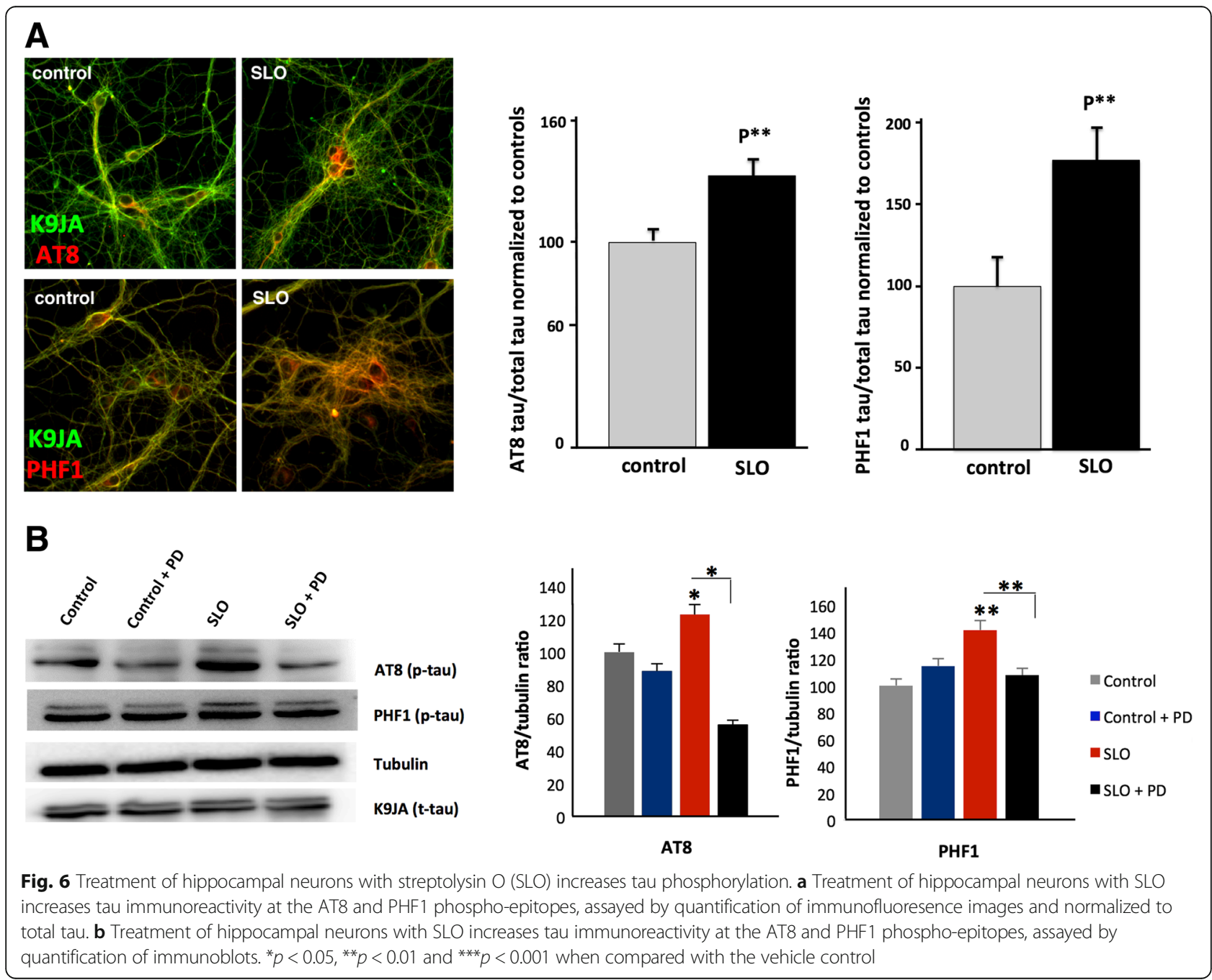


we sought to artificially stimulate this process by exposing hippocampal neurons to exogenous sphingomyelinase, a treatment that has previously been shown to promote the membrane repair process in HeLa cells [79]. We observed that hippocampal neurons treated with $2.5 \mathrm{mU} \mathrm{B.} \mathrm{cereus}$ sphingomyelinase had increased tau phosphorylation at both the AT8 and PHF1 epitopes, assayed either by immunofluorescence (Fig. 7a) or immunoblot (Fig. 7b).

\section{Visualization of toxic $A \beta$ oligomers using fluorescent biarsenical labeling}

The ability of $A \beta$ to form ion-permeable pores in synthetic membranes is blocked by the Gly ${ }^{37}$ Leu substitution, an observation that supports the "glycine zipper" model of A $\beta$ multimerization [41]. We have previously shown that $\mathrm{A} \beta \mathrm{Gly}^{37}$ Leu oligomers cannot induce tau hyperphosphorylation in hippocampal neurons [20], and we show in the present study that this substitution prevents the induction of membrane repair in a C. elegans model. These observations are consistent with the idea that the Gly ${ }^{37}$ Leu substitution interferes with the assembly of $\mathrm{A} \beta$ multimers capable of inducing membrane repair and subsequent downstream tau hyperphosphorylation, even though they do not directly demonstrate that this substitution interferes with $A \beta$ multimerization per se. To demonstrate this directly, we sought a means to label multimeric $A \beta$ specifically by taking advantage of the way that biarsenical compounds interact with appropriately positioned Cys residues. The ability of pairs of di-cysteine residues to coordinate the binding of biarsenical small molecules can be used to fluorescently label proteins tagged with a tetra-cysteine motif (FlAsH and ReAsH labeling, [1]). Subsequent studies demonstrated that di-cysteine residues located in different protein domains

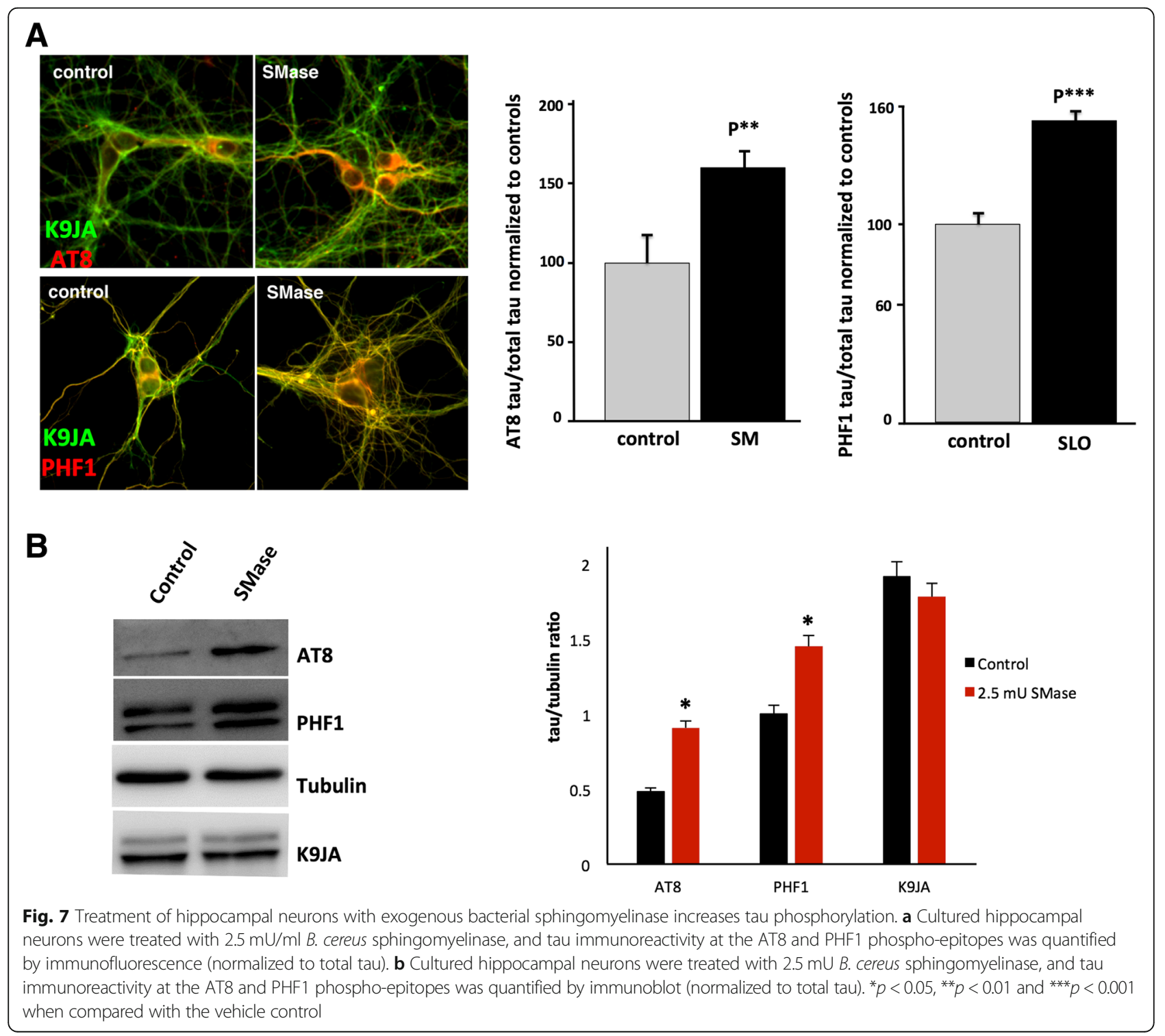


can also bind biarsenical fluorescent compounds if the di-cysteine residues are appropriately positioned in the protein [53]. The glycine zipper model predicts that $\alpha$-helical interactions in a lipid environment will pair $A \beta$ monomers such that their $C$-termini will be closely opposed, potentially allowing binding of biarsenical fluorescent probes (Fig. 8a).

We synthesized both wild type and $\mathrm{Gly}^{37} \mathrm{Leu} \mathrm{A} \beta$ 1-42 tagged with two cysteine residues at the $\mathrm{C}$-terminus. The addition of the C-terminal cysteines did not prevent wild type $A \beta$ from inducing tau phosphorylation in hippocampal neurons (Additional file 1: Figure S3 A). Furthermore, $E$. coli engineered to express the two-Cys version of wild type, but not Gly ${ }^{37} \mathrm{Leu}, \mathrm{A} \beta$, induced endocytosis in the C. elegans model (Additional file 1: Figure S3B). We exposed hippocampal neurons to these Cys-tagged peptides using the same protocols we used previously to assay $A \beta$ induction of tau. After $1 \mathrm{~h}$ exposure to $A \beta$ oligomer preps, the cultured neurons were stained with 1:800 FlAsH dye for $30 \mathrm{~min}$, then fixed, permeabilized and immunostained for $\mathrm{A} \beta$ ( $\mathrm{mAb}$ 6E10) (see Methods). When imaged by super-resolution microscopy, neurons exposed to (untagged) $A \beta$ 1-42 had foci of $A \beta$ immuno-reactivity associated with neuronal processes, but as expected these rarely overlapped with the FlAsH reagent signal (Fig. 8b). In contrast, a number of $\mathrm{A} \beta$-positive foci co-stained with the FlAsH reagent when the neurons were exposed to Cys-tagged $A \beta 1-42$ (Fig. 8c). Importantly, these co-staining-foci were reduced to the level of the untagged $A \beta$ control in neurons exposed to Cys-tagged $A \beta$ Gly $^{37}$ Leu (Fig. 8d, quantified in Fig. 8e). We interpret this result to indicate that the Gly ${ }^{37}$ Leu substitution interferes with the $A \beta$ multimerization required to interact with the FlAsH reagent.

\section{Discussion}

We have developed a novel $C$. elegans model to investigate the cellular response to exogenous $A \beta$, and we observe an induction of endocytosis similar to that associated with membrane repair in response to exposure to the CRY5B pore-forming toxin [31, 38, 52, 85]. The observations that $A \beta$ induction of endocytosis is blocked by a mutation in a gene encoding acid sphingomyelinase and the apparent membrane association of $A \beta$ in induced endosomes also support the view that exogenous $A \beta$ induces a membrane repair process as described in Fig. 1. To link membrane damage/repair with a classic marker of AD pathology, we also show that hippocampal neurons exposed to either a pore-forming toxin (streptolysin $\mathrm{O}$ ) or exogenous sphingomyelinase display increased tau hyperphosphorylation comparable to that seen after exposure to $A \beta$. In addition, the increase in endosomes induced by either $A \beta$ or CRY5B is inhibited by a loss-of-function mutation in $c l p-4$ and enhanced by mutations in amph-1 or unc-11, which are orthologs of human LOAD genes BIN1 and PICALM, respectively. These results further tie the membrane damage/repair process to Alzheimer's disease. Despite these similarities between the effects of $A \beta$-and CRY5B, feeding wild type worms $A \beta$-expressing $E$. coli does not result in the lethality observed in worms fed CRY5B. We attribute this difference to CRY5B being an evolved "professional" pore-forming toxin, assembled by a large protein that produces a pore size likely to be significantly larger [70] than a pore formed by $A \beta$ oligomers. At present we cannot determine if the effects of $A \beta$ in this model are due solely to the direct interaction of the peptide with the intestinal membrane, or whether
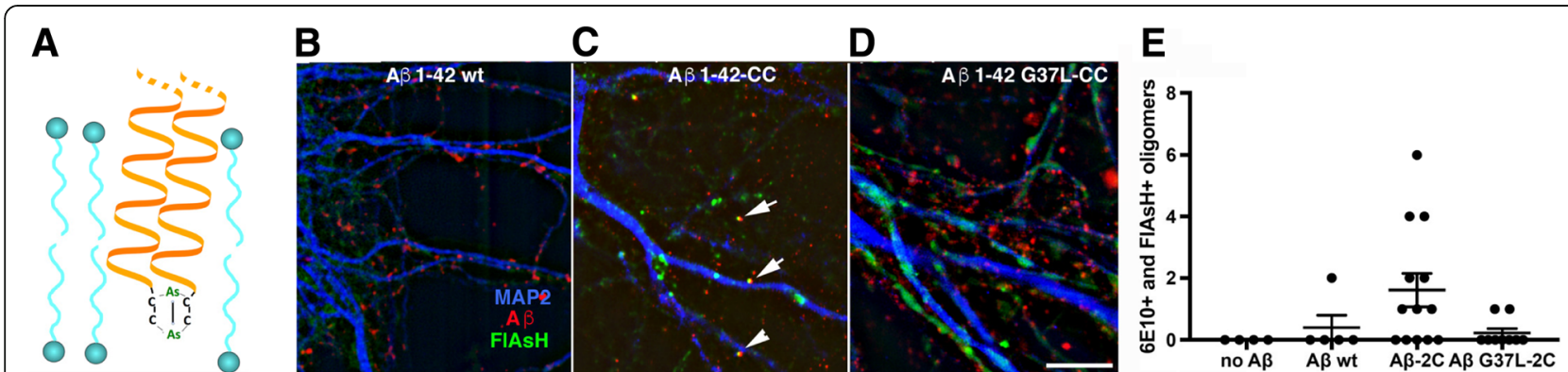

Fig. 8 Biarsenical dye staining of dicysteine-tagged synthetic wild type and Gly ${ }^{37}$ Leu variant $A \beta_{1-42}$ in cultured hippocampal neurons. a Schematic model of how membrane-associated A $\beta$ dimers in a parallel a-helical arrangement could bind the biarsenical FIAsH reagent. b Super-resolution image of cultured hippocampal neurons exposed to synthetic wild type $A \beta_{1-42}$, treated with FIAsH reagent, fixed, permeabilized, and probed with anti-A $\beta$ antibody 6E10. Note minimal association of FIAsH signal with A $\beta$ immunoreactivity, expected because this synthetic peptide does not contain dicysteines. c Same experiment as described for panel "B", except treatment with synthetic dicysteine-tagged wild type A 3 . Note multiple foci of colocalized FIAsH and A $\beta$ staining (arrows). $\mathbf{d}$ Same experiment as described for panel "B", except treatment with synthetic dicysteine-tagged Gly ${ }^{37} L e u A \beta$. Note this substitution prevents the formation of co-staining foci, supporting the hypothesis that the Gly ${ }^{37}$ Leu substitution inhibits the assembly of (potentially pore-forming) multimers. (The increased neuronal process-associated FIAsH signal in the Gly ${ }^{37}$ Leu A -treated cultures may reflect increased non-specific uptake of the FIAsH dye, because neurons treated with the non-toxic Gly ${ }^{37}$ Leu $A \beta$ are healthier than neurons treated with wild type $A \beta$ peptides.) e Quantification of co-labeling foci from multiple image fields acquired in the experiments described in $\mathbf{b}-\mathbf{d}$ 
proteins in the lumenal membrane are playing a role. We can conclude that suggested $A \beta$ receptors (e.g., prion protein, NMDA glutamate receptors, $\alpha 7 \mathrm{nAChR}$ ) are highly unlikely to be involved, as there is no evidence these proteins are expressed in the C. elegans intestine.

The ability of the $c l p-4$ deletion to prevent endocytosis induced by $A \beta$ or CRY5B implicates calpain activity in the membrane repair process. Calpains are known to target a number of cytoskeletal proteins [22], and to moderate cytoskeletal rearrangement, for example in focal adhesion remodeling [45]. Interestingly, in macrophages, calpain 2 cleavage of talin 1 is critical for endocytosis of the pore-forming "protective antigen" toxin produced by Bacillus anthracis [33]. We envision calpain activation as a conserved process required to induce local cytoskeletal changes that promote endocytosis in response to membrane damage.

The increased accumulation of $A \beta$-induced intestinal endosomes in the amph-1 and unc-11 mutants could result from either increased endosome formation or reduced endosome disassembly (or both). Loss of amph-1 alters the distribution of the early endosome marker RAB-5 and leads to increases in the size of steady-state endosomes in the C. elegans intestine [49]. We note that an increase in the number and size of RAB- 5 endosomes in AD brains has long been recognized [12]. BIN1, the ortholog of amph-1, has been implicated in the regulation of endocytosis in multiple contexts [65, 83, 86], even though its specific role in Alzheimer's disease is unclear. The rs59335482 risk allele, a 3 bp insertion upstream of the BIN1 coding sequence, increases BIN1 transcription and is correlated with tau but not $\beta$-amyloid loads in AD brains [13]. This study also reported that loss of Amph (the Drosophila ortholog of $B I N 1)$ suppressed tau pathology, but not $A \beta$ pathology, in transgenic fly models based on ectopic expression of these $\mathrm{AD}$-associated proteins in the fly eye. However, studies in mammalian neurons have indicated that loss of BIN1 promoted the propagation of tau pathology [9]. Our studies cannot resolve the discrepancies between these reports, but they do establish that amph-1 in $C$. elegans (and potentially BIN1 in mammals) play a role in the membrane repair response to pore-forming toxins.

unc-11 encodes a C. elegans clathrin adaptor protein orthologous to AP180 and PICALM, two closely related mammalian proteins. The unc-11 gene is expressed at high levels in neurons and at lower levels in other tissues, including the intestine. Interestingly, null alleles of unc-11 do not prevent endocytosis of synaptic membrane, but do result in an increased size of synaptic endosomes [63]. Similarly, RNAi knockdown of PICALM in mammalian neurons leads to synaptic vesicles with variably increased size [69], suggesting that these proteins primarily regulate the sorting and recycling of endosomes rather than endocytosis per se. Thus, the increase of endosome number (and size) in the intestines of unc-11 mutants exposed to CRY5B or A $\beta$ likely results from altered endosome sorting or disassembly rather than upregulated endocytosis. Most studies support the view that PICALM expression is protective in $\mathrm{AD}$, as full-length PICALM has been reported to be reduced in AD brain [3], and the protective allele of the primary AD-related SNP (rs3851179) is reported to increase PICALM mRNA levels in the brain [66].

The involvement of BIN1 and PICALM in endocytic processes has led multiple research groups to investigate their possible role in the production of $A \beta$, which largely occurs during the endocytic recycling of Amyloid Precursor Protein (APP) [56]. Indeed, loss of BIN1 has been reported to increase the production of $A \beta[3,60]$, whereas knockdown of PICALM is reported to reduce $\mathrm{A} \beta$ production $[37,80]$. If, as described above, the risk alleles of BIN1 and PICALM lead to increased and decreased expression of these two genes, respectively, then the reported effects of these genes on $A \beta$ production are actually the opposite of what might be expected. Our studies explore an alternative (but not mutually exclusive) explanation for the association of these genes with $\mathrm{AD}$ risk: a role in the cellular response to extracellular $\mathrm{A} \beta$. We find that loss of function mutations in amph-1 or unc-11 sensitize worms to the CRY5B pore-forming toxin (Fig. 5b), and lead to similar dysregulation of the endocytosis induced by CRY5B or $A \beta$. These results are consistent with BIN1 and PICALM risk alleles acting by modulating cellular responses to extracellular $A \beta$.

The ability of asm-1 mutations to suppress $\mathrm{A} \beta$ - or CRY5B-induced endocytosis supports the view that $A \beta$ can instigate a membrane repair process analogous to that occurring in mammalian cells challenged by a pore-forming toxin such as SLO [32]. We reasoned that if $\mathrm{A} \beta$ acts as a pore-forming toxin in the AD brain, known effects of $A \beta$ exposure such as tau hyperphosphorylation might be replicated using pore-forming toxins. We find that exposure of rat hippocampal neurons to SLO results in calpain-dependent tau hyperphosphorylation at two epitopes classically associated with $\mathrm{AD}$ pathology. Although we cannot exclude the possibility that SLO mimics $\mathrm{A} \beta$-induced tau phosphorylation by an unrelated pathway, the ability of exogenous sphingomeylinase to induce tau hyperphosphorylation supports the view that tau hyperphosphorylation can be a downstream consequence of membrane damage/repair. Attempts to induce endocytosis in $C$. elegans intestines by feeding worms $B$. cereus sphingomeylinase were unsuccessful, possibly due to reduced activity of the enzyme at the lower temperature required for worm maintenance $\left(20^{\circ} \mathrm{C}\right.$ for C. elegans vs. $37^{\circ} \mathrm{C}$ for cultured neurons) and/or degradation of the enzyme in the intestinal lumen. Our experiments examining the 
effects of exogenous sphingomeylinase on tau hyperphophorylation also cannot determine if sphingomeylin-based secondary messengers are playing a role. Similarly, determining whether tau phosphorylation is a functional component of membrane repair or simply an incidental consequence will require additional investigation.

A major observation supporting the possible relevance of toxic $A \beta$ pores is the dramatically reduced toxicity of the $A \beta$ Gly ${ }^{37}$ Leu variant in both transgenic C. elegans models and mammalian neurons [20]. This variant, which unlike wild type $A \beta$ cannot induce ion-permeable channels in synthetic membranes, was investigated by the Bowie lab based on modeling studies that suggested it could not assemble pore-forming oligomers due to interference with a "glycine zipper" motif [41]. However, it had not been demonstrated previously that the Gly substitution in this critical variant actually alters $A \beta$ multimerization, and in fact the Gly ${ }^{37}$ Leu substitution does not reduce the stable oligomer species assayed by SDS-PAGE (see Additional file 1: Figure S1C). We therefore sought an approach to assay $A \beta$ multimerization in vivo that could capture potentially less stable, membrane-associated oligomers. Using hippocampal neurons exposed to dicysteine-tagged synthetic $A \beta$ and detection of closely associated pairs of dicysteine tags by means of a membrane-permeant biarsenical dye, we provide evidence that the Gly ${ }^{37}$ Leu substitution does indeed inhibit $A \beta$ multimerization in a cellular context. We suggest that the $\mathrm{A} \beta \mathrm{Gly}^{37}$ Leu variant can be used as a control peptide for investigating $A \beta$ oligomer effects and could be superior to typical $A \beta$ sequence-scrambled peptides used for this purpose.

More than 20 years ago, the discovery by Arispe and colleagues that $A \beta$ could form ion channels in synthetic membranes led them to propose that $\mathrm{A} \beta$ membrane pores could contribute to Alzheimer pathology [6]. While multiple studies since have been supportive [36], this hypothesis has neither been directly supported (e.g., by the visualization of $A \beta$ pores in $A D$ pathological tissue), nor convincingly discounted. The failure to visualize $A \beta$ pores in $\mathrm{AD}$ brains may not be surprising given the rapidity with which membrane pores are removed in mammalian cells ( $<1$ min in HEK293 cells; [32]), whereas the consequences of the repair process, such as hyperphosphorylation of tau, might accumulate. Our studies cannot directly prove the disease relevance of the pore-forming capacity of $A \beta$, but they do suggest a possible re-interpretation of existing human data. In particular, the demonstration of tau hyperphosphorylation as a downstream consequence of membrane damage/repair suggests mechanisms that may also be in play in non-AD tauopathies such as Chronic Traumatic Encephalopathy (CTE) and Niemann Pick type C disease [64]. Multiple explanations have been advanced to explain the dramatically increased AD risk for ApoE4 allele carriers (reviewed in [48]); our results support the idea that this risk could be due to altered membrane repair resulting from the reduced cholesterol and phospholipid secretion observed in APOE4 glia and neurons [54].

\section{Additional files}

Additional file 1: Supplementary Figures. (DOCX 919 kb)

Additional file 2: Individual Experiment Data. (XLSX 21 kb)

\section{Acknowledgements}

This work was supported by US National Institutes of Health award R21 AG049693 to CDL and Natural Science and Engineering Research Council of Canada (327100) and the Canadian Institutes of Health Research (90396) awards to MAS. We would like to thank Andrew Gaines and Josh Morgenstern for assistance with pilot experiments. Some nematode strains were provided by the Caenorhabditis Genetics Center, funded by the NIH National Center for Research Resources. We would also like to thank Dr. Raffi Aroian for providing the CRY5B expression vector.

\section{Authors' contributions}

CJ designed and performed both C. elegans and hippocampal neuron experiments, and contributed to the writing of this manuscript. CT performed C. elegans experiments, including the CRY5B survival studies. CMR constructed and characterized the E. coli strains expressing human A $\beta$. AA performed hippocampal neuron experiments, including tau immunoblots. GHS designed and performed hippocampal neuron experiments and contributed to the writing of this manuscript. MAS and CDL contributed to experimental design and the writing of the manuscript. All authors have read and approved of this manuscript.

\section{Competing interests}

The authors declare that they have no competing interests.

\section{Publisher's Note}

Springer Nature remains neutral with regard to jurisdictional claims in published maps and institutional affiliations.

\section{Author details}

${ }^{1}$ Department of Integrative Physiology, University of Colorado at Boulder, Boulder, CO, USA. ${ }^{2}$ Department of Biological Sciences, and the Centre for Cell Biology, Development, and Disease, Simon Fraser University, Burnaby, British Columbia, Canada. ${ }^{3}$ Department of Molecular, Cellular, and Developmental Biology, University of Colorado, Boulder, Colorado 80309-0347, USA. ${ }^{4}$ Centre de Recherche en Sciences Animales de Deschambault (CRSAD), Deschambault, Quebec G0A 1S0, Canada. ${ }^{5}$ Centre for Cell Biology, Development, and Disease), Simon Fraser University, British Columbia V5A 1S6, Burnaby, Canada.

Received: 21 October 2018 Accepted: 13 November 2018 Published online: 29 November 2018

\section{References}

1. Adams SR, Campbell RE, Gross LA, Martin BR, Walkup GK, Yao Y, Llopis J, Tsien RY (2002) New biarsenical ligands and tetracysteine motifs for protein labeling in vitro and in vivo: synthesis and biological applications. J Am Chem Soc 124:6063-6076

2. Alberdi E, Sanchez-Gomez MV, Cavaliere F, Perez-Samartin A, Zugaza JL, Trullas R, Domercq M, Matute C (2010) Amyloid beta oligomers induce Ca2+ dysregulation and neuronal death through activation of ionotropic glutamate receptors. Cell Calcium 47:264-272. https://doi.org/10.1016/j.ceca.2009.12.010

3. Ando K, Brion JP, Stygelbout V, Suain V, Authelet M, Dedecker R, Chanut A, Lacor P, Lavaur J, Sazdovitch V et al (2013) Clathrin adaptor CALM/PICALM is associated with neurofibrillary tangles and is cleaved in Alzheimer's brains. Acta Neuropathol 125:861-878. https:/doi.org/10.1007/s00401-013-1111-z

4. Anekonda TS, Quinn JF, Harris C, Frahler K, Wadsworth TL, Woltjer RL (2011) L-type voltage-gated calcium channel blockade with isradipine as a therapeutic strategy for Alzheimer's disease. Neurobiol Dis 41:62-70. https:// doi.org/10.1016/j.nbd.2010.08.020 
5. Arbel-Ornath M, Hudry E, Boivin JR, Hashimoto T, Takeda S, Kuchibhotla KV, Hou S, Lattarulo CR, Belcher AM, Shakerdge N et al (2017) Soluble oligomeric amyloid-beta induces calcium dyshomeostasis that precedes synapse loss in the living mouse brain. Mol Neurodegener 12:27. https://doi. org/10.1186/s13024-017-0169-9

6. Arispe N, Pollard HB, Rojas E (1993) Giant multilevel cation channels formed by Alzheimer disease amyloid beta-protein [A beta P-(1-40)] in bilayer membranes. Proc Natl Acad Sci U S A 90:10573-10577

7. Bate C, Williams A (2011) Amyloid-beta-induced synapse damage is mediated via cross-linkage of cellular prion proteins. J Biol Chem 286: 37955-37963. https://doi.org/10.1074/jbc.M111.248724

8. Brenner S (1974) The genetics of Caenorhabditis elegans. Genetics 77:71-94

9. Calafate S, Flavin W, Verstreken P, Moechars D (2016) Loss of Bin1 promotes the propagation of tau pathology. Cell Rep 17:931-940. https://doi.org/10. 1016/j.celrep.2016.09.063

10. Carrasquillo MM, Belbin O, Hunter TA, Ma L, Bisceglio GD, Zou F, Crook JE, Pankratz VS, Sando SB, Aasly JO et al (2011) Replication of BIN1 association with Alzheimer's disease and evaluation of genetic interactions. J Alzheimers Dis 24:751-758. https://doi.org/10.3233/JAD-2011-101932

11. Castaneda MT, Lopez ED, Touhami A, Tovar R, Ortega MR, Rodriguez JM (2015) Neuroprotection of medial septal cholinergic neurons by memantine after intralateral septal injection of Abeta1-40. Neuroreport 26:450-454. https://doi.org/10.1097/WNR.0000000000000364

12. Cataldo AM, Barnett JL, Pieroni C, Nixon RA (1997) Increased neuronal endocytosis and protease delivery to early endosomes in sporadic Alzheimer's disease: neuropathologic evidence for a mechanism of increased beta-amyloidogenesis. J Neurosci 17:6142-6151

13. Chapuis J, Hansmannel F, Gistelinck M, Mounier A, Van Cauwenberghe C, Kolen KV, Geller F, Sottejeau Y, Harold D, Dourlen P et al (2013) Increased expression of BIN1 mediates Alzheimer genetic risk by modulating tau pathology. Mol Psychiatry 18:1225-1234. https://doi.org/ 10.1038/mp.2013.1

14. De Felice FG, Wu D, Lambert MP, Fernandez SJ, Velasco PT, Lacor PN, Bigio EH, Jerecic J, Acton PJ, Shughrue PJ et al (2008) Alzheimer's disease-type neuronal tau hyperphosphorylation induced by A beta oligomers. Neurobiol Aging 29:1334-1347. https://doi.org/10.1016/j.neurobiolaging.2007.02.029

15. Deng J, Habib A, Obregon DF, Barger SW, Giunta B, Wang YJ, Hou H, Sawmiller D, Tan J (2015) Soluble amyloid precursor protein alpha inhibits tau phosphorylation through modulation of GSK3beta signaling pathway. J Neurochem 135:630-637. https://doi.org/10.1111/jnc.13351

16. Diomede L, Di Fede G, Romeo M, Bagnati R, Ghidoni R, Fiordaliso F, Salio M, Rossi A, Catania M, Paterlini A et al (2014) Expression of A2V-mutated Abeta in Caenorhabditis elegans results in oligomer formation and toxicity. Neurobiol Dis 62:521-532. https://doi.org/10.1016/j.nbd.2013.10.024

17. Dosanjh LE, Brown MK, Rao G, Link CD, Luo Y (2010) Behavioral phenotyping of a transgenic Caenorhabditis elegans expressing neuronal amyloid-beta. J Alzheimers Dis 19:681-690. https://doi.org/10.3233/JAD-2010-1267

18. Duan Z, Sesti F (2013) A Caenorhabditis elegans model system for amylopathy study. J Vis Exp:e50435. https://doi.org/10.3791/50435

19. Etxaniz A, Gonzalez-Bullon D, Martin C, Ostolaza H (2018) Membrane repair mechanisms against Permeabilization by pore-forming toxins. Toxins (Basel) 10. https://doi.org/10.3390/toxins10060234

20. Fonte V, Dostal V, Roberts CM, Gonzales P, Lacor PN, Velasco PT, Magrane J, Dingwell N, Fan EY, Silverman MA et al (2011) A glycine zipper motif mediates the formation of toxic beta-amyloid oligomers in vitro and in vivo. Mol Neurodegener 6:61. https://doi.org/10.1186/1750-1326-6-61

21. Goedert M, Baur CP, Ahringer J, Jakes R, Hasegawa M, Spillantini MG, Smith MJ, Hill F (1996) PTL-1, a microtubule-associated protein with tau-like repeats from the nematode Caenorhabditis elegans. J Cell Sci 109(Pt 11): 2661-2672

22. Goll DE, Thompson VF, Li H, Wei W, Cong J (2003) The calpain system. Physiol Rev 83:731-801. https://doi.org/10.1152/physrev.00029.2002

23. Grueninger F, Bohrmann B, Czech C, Ballard TM, Frey JR, Weidensteiner C, von Kienlin M, Ozmen L (2010) Phosphorylation of Tau at S422 is enhanced by Abeta in TauPS2APP triple transgenic mice. Neurobiol Dis 37:294-306. https://doi.org/10.1016/j.nbd.2009.09.004

24. Guivernau B, Bonet J, Valls-Comamala V, Bosch-Morato M, Godoy JA, Inestrosa NC, Peralvarez-Marin A, Fernandez-Busquets X, Andreu D, Oliva B et al (2016) Amyloid-beta Peptide Nitrotyrosination Stabilizes Oligomers and Enhances NMDAR-Mediated Toxicity. J Neurosci 36:11693-11703. https://doi. org/10.1523/JNEUROSCI.1081-16.2016
25. Hardy J, Selkoe DJ (2002) The amyloid hypothesis of Alzheimer's disease: progress and problems on the road to therapeutics. Science 297:353-356. https://doi.org/10.1126/science.1072994

26. Hassan WM, Dostal V, Huemann BN, Yerg JE, Link CD (2015) Identifying Abeta-specific pathogenic mechanisms using a nematode model of Alzheimer's disease. Neurobiol Aging 36:857-866. https://doi.org/10.1016/j. neurobiolaging.2014.10.016

27. Hernandez F, Lucas JJ, Avila J (2013) GSK3 and tau: two convergence points in Alzheimer's disease. J Alzheimers Dis 33(Suppl 1):S141-S144. https://doi. org/10.3233/JAD-2012-129025

28. Herrup K (2015) The case for rejecting the amyloid cascade hypothesis. Nat Neurosci 18:794-799. https://doi.org/10.1038/nn.4017

29. Hirakura Y, Lin MC, Kagan BL (1999) Alzheimer amyloid abeta1-42 channels: effects of solvent, $\mathrm{pH}$, and Congo red. J Neurosci Res 57:458-466

30. Ho R, Ortiz D, Shea TB (2001) Amyloid-beta promotes calcium influx and neurodegeneration via stimulation of $L$ voltage-sensitive calcium channels rather than NMDA channels in cultured neurons. J Alzheimers Dis 3:479-483

31. Huffman DL, Abrami L, Sasik R, Corbeil J, van der Goot FG, Aroian RV (2004) Mitogen-activated protein kinase pathways defend against bacterial poreforming toxins. Proc Natl Acad Sci U S A 101:10995-11000. https://doi.org/ 10.1073/pnas.0404073101

32. Idone V, Tam C, Goss JW, Toomre D, Pypaert M, Andrews NW (2008) Repair of injured plasma membrane by rapid Ca2+-dependent endocytosis. J Cell Biol 180:905-914. https://doi.org/10.1083/jcb.200708010

33. Jeong SY, Martchenko M, Cohen SN (2013) Calpain-dependent cytoskeletal rearrangement exploited for anthrax toxin endocytosis. Proc Natl Acad Sci U S A 110:E4007-E4015. https://doi.org/10.1073/pnas.1316852110

34. Jin N, Yin X, Yu D, Cao M, Gong CX, lqbal K, Ding F, Gu X, Liu F (2015) Truncation and activation of GSK-3beta by calpain I: a molecular mechanism links to tau hyperphosphorylation in Alzheimer's disease. Sci Rep 5:8187. https://doi.org/10.1038/srep08187

35. Kaech S, Banker G (2006) Culturing hippocampal neurons. Nat Protoc 1: 2406-2415. https://doi.org/10.1038/nprot.2006.356

36. Kagan BL (2012) Membrane pores in the pathogenesis of neurodegenerative disease. Prog Mol Biol Transl Sci 107:295-325. https:// doi.org/10.1016/B978-0-12-385883-2.00001-1

37. Kanatsu K, Hori Y, Takatori S, Watanabe T, Iwatsubo T, Tomita T (2016) Partial loss of CALM function reduces Abeta42 production and amyloid deposition in vivo. Hum Mol Genet 25:3988-3997. https://doi.org/10.1093/hmg/ddw239

38. Kao CY, Los FC, Huffman DL, Wachi S, Kloft N, Husmann M, Karabrahimi V, Schwartz JL, Bellier A, Ha C et al (2011) Global functional analyses of cellular responses to pore-forming toxins. PLoS Pathog 7:e1001314. https://doi.org/ 10.1371/journal.ppat.1001314

39. Karran E, De Strooper B (2016) The amyloid cascade hypothesis: are we poised for success or failure? J Neurochem 139(Suppl 2):237-252. https:// doi.org/10.1111/jnc.13632

40. Kim JA, Kim HL (2001) Cell-free expression and functional reconstitution of CALM in clathrin assembly. Exp Mol Med 33:89-94. https://doi.org/10.1038/ emm.2001.16

41. Kim S, Jeon TJ, Oberai A, Yang D, Schmidt JJ, Bowie JU (2005) Transmembrane glycine zippers: physiological and pathological roles in membrane proteins. Proc Natl Acad Sci U S A 102:14278-14283. https://doi.org/10.1073/pnas.0501234102

42. Kurbatskaya K, Phillips EC, Croft CL, Dentoni G, Hughes MM, Wade MA, AlSarraj S, Troakes C, O'Neill MJ, Perez-Nievas BG et al (2016) Upregulation of calpain activity precedes tau phosphorylation and loss of synaptic proteins in Alzheimer's disease brain. Acta Neuropathol Commun 4:34. https://doi. org/10.1186/s40478-016-0299-2

43. Lambert MP, Viola KL, Chromy BA, Chang L, Morgan TE, Yu J, Venton DL, Krafft GA, Finch CE, Klein WL (2001) Vaccination with soluble Abeta oligomers generates toxicity-neutralizing antibodies. J Neurochem 79:595-605

44. Lauren J, Gimbel DA, Nygaard HB, Gilbert JW, Strittmatter SM (2009) Cellular prion protein mediates impairment of synaptic plasticity by amyloid-beta oligomers. Nature 457:1128-1132. https://doi.org/10.1038/nature07761

45. Lebart MC, Benyamin Y (2006) Calpain involvement in the remodeling of cytoskeletal anchorage complexes. FEBS J 273:3415-3426. https://doi.org/10. 1111/j.1742-4658.2006.05350.x

46. Lin H, Bhatia R, Lal R (2001) Amyloid beta protein forms ion channels: implications for Alzheimer's disease pathophysiology. FASEB J 15:2433-2444. https://doi.org/10.1096/fj.01-0377com

47. Link CD (1995) Expression of human beta-amyloid peptide in transgenic Caenorhabditis elegans. Proc Natl Acad Sci U S A 92:9368-9372 
48. Liu CC, Liu CC, Kanekiyo T, Xu H, Bu G (2013) Apolipoprotein E and Alzheimer disease: risk, mechanisms and therapy. Nat Rev Neurol 9:106-118. https://doi.org/10.1038/nrneurol.2012.263

49. Liu O, Grant BD (2015) Basolateral endocytic recycling requires RAB-10 and AMPH-1 mediated recruitment of RAB-5 GAP TBC-2 to endosomes. PLoS Genet 11:e1005514. https://doi.org/10.1371/journal.pgen.1005514

50. Liu SL, Wang C, Jiang T, Tan L, Xing A, Yu JT (2016) The role of Cdk5 in Alzheimer's disease. Mol Neurobiol 53:4328-4342. https://doi.org/10.1007/ s12035-015-9369-x

51. Lopes JP, Oliveira CR, Agostinho P (2010) Neurodegeneration in an Abetainduced model of Alzheimer's disease: the role of Cdk5. Aging Cell 9:64-77. https://doi.org/10.1111/j.1474-9726.2009.00536.x

52. Los FC, Kao CY, Smitham J, McDonald KL, Ha C, Peixoto CA, Aroian RV (2011) RAB-5- and RAB-11-dependent vesicle-trafficking pathways are required for plasma membrane repair after attack by bacterial poreforming toxin. Cell Host Microbe 9:147-157. https://doi.org/10.1016/j. chom.2011.01.005

53. Luedtke NW, Dexter RJ, Fried DB, Schepartz A (2007) Surveying polypeptide and protein domain conformation and association with FIAsH and $\mathrm{ReAsH}$. Nat Chem Biol 3:779-784. https://doi.org/10.1038/nchembio.2007.49

54. Mahley RW (2016) Central nervous system lipoproteins: ApoE and regulation of cholesterol metabolism. Arterioscler Thromb Vasc Biol 36:1305-1315. https://doi.org/10.1161/ATVBAHA.116.307023

55. Mairet-Coello G, Courchet J, Pieraut S, Courchet V, Maximov A, Polleux F (2013) The CAMKK2-AMPK kinase pathway mediates the synaptotoxic effects of Abeta oligomers through Tau phosphorylation. Neuron 78:94-108. https://doi.org/10.1016/j.neuron.2013.02.003

56. Manucat-Tan NB, Saadipour K, Wang YJ, Bobrovskaya L, Zhou XF (2018) Cellular trafficking of amyloid precursor protein in Amyloidogenesis physiological and pathological significance. Mol Neurobiol. https://doi.org/ 10.1007/s12035-018-1106-9

57. Martin L, Latypova X, Wilson CM, Magnaudeix A, Perrin ML, Yardin C, Terro F (2013) Tau protein kinases: involvement in Alzheimer's disease. Ageing Res Rev 12:289-309. https://doi.org/10.1016/j.arr.2012.06.003

58. Meng L, Zhang A, Jin Y, Yan D (2016) Regulation of neuronal axon specification by glia-neuron gap junctions in C. elegans. Elife 5. https://doi. org/10.7554/eLife.19510

59. Miranda CJ, Braun L, Jiang Y, Hester ME, Zhang L, Riolo M, Wang H, Rao M, Altura RA, Kaspar BK (2012) Aging brain microenvironment decreases hippocampal neurogenesis through Wnt-mediated survivin signaling. Aging Cell 11:542-552. https://doi.org/10.1111/j.1474-9726.2012.00816.x

60. Miyagawa T, Ebinuma I, Morohashi Y, Hori Y, Young Chang M, Hattori H, Maehara T, Yokoshima S, Fukuyama T, Tsuji S et al (2016) BIN1 regulates BACE1 intracellular trafficking and amyloid-beta production. Hum Mol Genet 25:2948-2958. https://doi.org/10.1093/hmg/ddw146

61. Naj AC, Jun G, Reitz C, Kunkle BW, Perry W, Park YS, Beecham GW Rajbhandary RA, Hamilton-Nelson KL, Wang LS et al (2014) Effects of multiple genetic loci on age at onset in late-onset Alzheimer disease: a genome-wide association study. JAMA Neurol 71:1394-1404. https://doi. org/10.1001/jamaneurol.2014.1491

62. Nikkel AL, Martino B, Markosyan S, Brederson JD, Medeiros R, Moeller A, Bitner RS (2012) The novel calpain inhibitor A-705253 prevents stressinduced tau hyperphosphorylation in vitro and in vivo. Neuropharmacology 63:606-612. https://doi.org/10.1016/j.neuropharm.2012.05.011

63. Nonet ML, Holgado AM, Brewer F, Serpe CJ, Norbeck BA, Holleran J, Wei L, Hartwieg E, Jorgensen EM, Alfonso A (1999) UNC-11, a Caenorhabditis elegans AP180 homologue, regulates the size and protein composition of synaptic vesicles. Mol Biol Cell 10:2343-2360. https://doi.org/10.1091/mbc.10.7.2343

64. Padamsey Z, McGuinness L, Emptage NJ (2017) Inhibition of lysosomal Ca(2+) signalling disrupts dendritic spine structure and impairs wound healing in neurons. Commun Integr Biol 10:e1344802. https://doi.org/10.1080/19420889. 2017.1344802

65. Pant S, Sharma M, Patel K, Caplan S, Carr CM, Grant BD (2009) AMPH-1/ Amphiphysin/Bin1 functions with RME-1/Ehd1 in endocytic recycling. Nat Cell Biol 11:1399-1410. https://doi.org/10.1038/ncb1986

66. Parikh I, Fardo DW, Estus S (2014) Genetics of PICALM expression and Alzheimer's disease. PLoS One 9:e91242. https://doi.org/10.1371/journal.pone.0091242

67. Peters C, Espinoza MP, Gallegos S, Opazo C, Aguayo LG (2015) Alzheimer's Abeta interacts with cellular prion protein inducing neuronal membrane damage and synaptotoxicity. Neurobiol Aging 36:1369-1377. https://doi. org/10.1016/j.neurobiolaging.2014.11.019
68. Peters C, Fernandez-Perez EJ, Burgos CF, Espinoza MP, Castillo C, Urrutia JC, Streltsov VA, Opazo C, Aguayo LG (2013) Inhibition of amyloid beta-induced synaptotoxicity by a pentapeptide derived from the glycine zipper region of the neurotoxic peptide. Neurobiol Aging 34:2805-2814. https://doi.org/10. 1016/j.neurobiolaging.2013.06.001

69. Petralia RS, Wang YX, Indig FE, Bushlin I, Wu F, Mattson MP, Yao PJ (2013) Reduction of AP180 and CALM produces defects in synaptic vesicle size and density. NeuroMolecular Med 15:49-60. https://doi.org/10.1007/s12017-012-8194-x

70. Peyronnet O, Vachon V, Schwartz JL, Laprade R (2001) lon channels induced in planar lipid bilayers by the bacillus thuringiensis toxin Cry1Aa in the presence of gypsy moth (Lymantria dispar) brush border membrane. J Membr Biol 184:45-54

71. de Planque MR, Raussens V, Contera SA, Rijkers DT, Liskamp RM, Ruysschaert JM, Ryan JF, Separovic F, Watts A (2007) Beta-sheet structured betaamyloid(1-40) perturbs phosphatidylcholine model membranes. J Mol Biol 368: 982-997 Doi https://doi.org/10.1016/j.jmb.2007.02.063

72. Reitz C Alzheimer's disease and the amyloid cascade hypothesis: a critical review Int J Alzheimers Dis 2012, 2012:369808. https://doi.org/10.1155/2012/369808

73. Resende R, Pereira C, Agostinho P, Vieira AP, Malva JO, Oliveira CR (2007) Susceptibility of hippocampal neurons to Abeta peptide toxicity is associated with perturbation of Ca2+ homeostasis. Brain Res 1143:11-21. https://doi.org/10.1016/j.brainres.2007.01.071

74. Rushworth JV, Griffiths HH, Watt NT, Hooper NM (2013) Prion proteinmediated toxicity of amyloid-beta oligomers requires lipid rafts and the transmembrane LRP1. J Biol Chem 288:8935-8951. https://doi.org/10.1074/ jbc.M112.400358

75. Seshadri S, Fitzpatrick AL, Ikram MA, DeStefano AL, Gudnason V, Boada M, Bis JC, Smith AV, Carassquillo MM, Lambert JC et al (2010) Genome-wide analysis of genetic loci associated with Alzheimer disease. JAMA 303:18321840. https://doi.org/10.1001/jama.2010.574

76. Seward ME, Swanson E, Norambuena A, Reimann A, Cochran JN, Li R, Roberson ED, Bloom GS (2013) Amyloid-beta signals through tau to drive ectopic neuronal cell cycle re-entry in Alzheimer's disease. J Cell Sci 126: 1278-1286. https://doi.org/10.1242/jcs.1125880

77. Small DH, Gasperini R, Vincent AJ, Hung AC, Foa L (2009) The role of Abetainduced calcium dysregulation in the pathogenesis of Alzheimer's disease. J Alzheimers Dis 16:225-233. https://doi.org/10.3233/JAD-2009-0951

78. Sul D, Kim HS, Lee D, Joo SS, Hwang KW, Park SY (2009) Protective effect of caffeic acid against beta-amyloid-induced neurotoxicity by the inhibition of calcium influx and tau phosphorylation. Life Sci 84:257-262. https://doi.org/ 10.1016/j.lfs.2008.12.001

79. Tam C, Idone V, Devlin C, Fernandes MC, Flannery A, He X, Schuchman E, Tabas I, Andrews NW (2010) Exocytosis of acid sphingomyelinase by wounded cells promotes endocytosis and plasma membrane repair. J Cell Biol 189:1027-1038. https://doi.org/10.1083/jcb.201003053

80. Thomas RS, Henson A, Gerrish A, Jones L, Williams J, Kidd EJ (2016) Decreasing the expression of PICALM reduces endocytosis and the activity of beta-secretase: implications for Alzheimer's disease. BMC Neurosci 17:50. https://doi.org/10.1186/s12868-016-0288-1

81. Town T, Zolton J, Shaffner R, Schnell B, Crescentini R, Wu Y, Zeng J, DelleDonne A, Obregon D, Tan J et al (2002) p35/Cdk5 pathway mediates soluble amyloid-beta peptide-induced tau phosphorylation in vitro. J Neurosci Res 69:362-372. https://doi.org/10.1002/jnr.10299

82. Treusch S, Hamamichi S, Goodman JL, Matlack KE, Chung CY, Baru V, Shulman JM, Parrado A, Bevis BJ, Valastyan JS et al (2011) Functional links between Abeta toxicity, endocytic trafficking, and Alzheimer's disease risk factors in yeast. Science 334:1241-1245. https://doi.org/10. 1126/science. 1213210

83. Ubelmann F, Burrinha T, Salavessa L, Gomes R, Ferreira C, Moreno N, Guimas Almeida C (2017) Bin1 and CD2AP polarise the endocytic generation of beta-amyloid. EMBO Rep 18:102-122. https://doi.org/10. 15252/embr.201642738

84. Wang Z, Lei H, Zheng M, Li Y, Cui Y, Hao F (2016) Meta-analysis of the association between Alzheimer disease and variants in GAB2, PICALM, and SORL1. Mol Neurobiol 53:6501-6510. https:/doi.org/10.1007/s12035-015-9546-y

85. Wei JZ, Hale K, Carta L, Platzer E, Wong C, Fang SC, Aroian RV (2003) Bacillus thuringiensis crystal proteins that target nematodes. Proc Natl Acad Sci U S A 100:2760-2765. https://doi.org/10.1073/pnas.0538072100

86. Yao J, Nowack A, Kensel-Hammes P, Gardner RG, Bajjalieh SM (2010) Cotrafficking of SV2 and synaptotagmin at the synapse. J Neurosci 30:55695578. https://doi.org/10.1523/JNEUROSCI.4781-09.2010 
87. Zempel H, Thies E, Mandelkow E, Mandelkow EM (2010) Abeta oligomers cause localized $\mathrm{Ca}(2+)$ elevation, missorting of endogenous Tau into dendrites, Tau phosphorylation, and destruction of microtubules and spines. J Neurosci 30:11938-11950. https://doi.org/10.1523/JNEUROSCI.2357-10.2010

88. Zhao WQ, Santini F, Breese R, Ross D, Zhang XD, Stone DJ, Ferrer M, Townsend M, Wolfe AL, Seager MA et al (2010) Inhibition of calcineurinmediated endocytosis and alpha-amino-3-hydroxy-5-methyl-4isoxazolepropionic acid (AMPA) receptors prevents amyloid beta oligomerinduced synaptic disruption. J Biol Chem 285:7619-7632. https://doi.org/10. 1074/jbc.M109.057182

89. Zhou M, Huang T, Collins N, Zhang J, Shen H, Dai X, Xiao N, Wu X, Wei Z, York J et al (2016) APOE4 induces site-specific Tau phosphorylation through Calpain-CDK5 signaling pathway in EFAD-Tg mice. Curr Alzheimer Res 13: 1048-1055

Ready to submit your research? Choose BMC and benefit from:

- fast, convenient online submission

- thorough peer review by experienced researchers in your field

- rapid publication on acceptance

- support for research data, including large and complex data types

- gold Open Access which fosters wider collaboration and increased citations

- maximum visibility for your research: over $100 \mathrm{M}$ website views per year

At $\mathrm{BMC}$, research is always in progress.

Learn more biomedcentral.com/submissions 